DOE/ER-0692

$63-19695(2)$

\title{
Advanced Energy Projects FY 1996 Research Summaries
}

September 1996

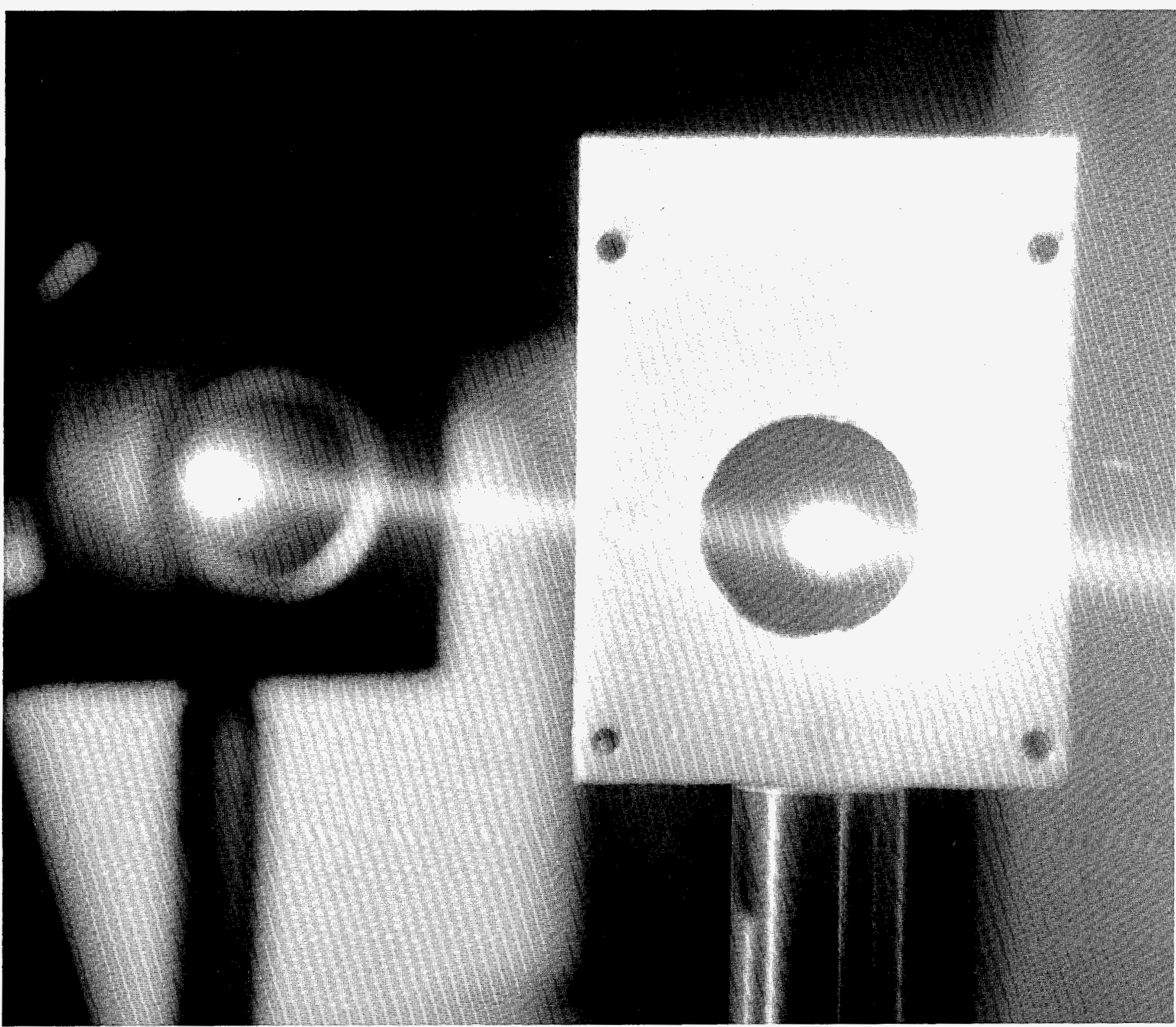

U.S. Department of Energy Office of Energy Research Office of Computational and Technology Research Advanced Energy Projects Division

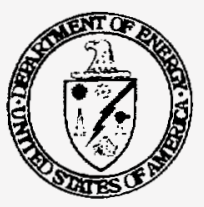




\section{Cover photograph courtesy of Gary P. Wiederrecht, Argonne National Laboratory}

The novel device shown on the cover is a photorefractive liquid crystal optical processor. The shown central window consists of the liquid crystalline composite sandwiched between two indium-tin-oxide coated glass plates. In the photograph, two laser beams traverse the material in order to form a hologram. The power source is a $1.5 \mathrm{~V}$ battery that can be sealed within a teflon housing. This research received a 1996 R\&D 100 Award sponsored by R\&D Magazine. (For more information, see abstract \#6 on page 9)

This report has been reproduced directly from the best available copy.

Available to DOE and DOE Contractors from the Office of Scientific and Technical Information, P.O. Box 62, Oak Ridge, TN 37831; prices available from (423) 576-8401.

Available to the public from the U.S. Department of Commerce, Technology Administration, National Technical Information Service, Springfield, VA 22161, (703) 4874650 


\section{Advanced Energy Projects FY 1996 Research Summaries}

September 1996

U.S. Department of Energy Office of Energy Research Office of Computational and Technology Research

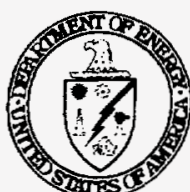
Advanced Energy Projects Division Germantown, MD 20874-1290 


\section{DISCLAIMER}

This report was prepared as an account of work sponsored by an agency of the United States Government. Neither the United States Government nor any agency thereof, nor any of their employees, makes any warranty, express or implied, or assumes any legal liability or responsibility for the accuracy, completeness, or usefulness of any information, apparatus, product, or process disclosed, or represents that its use would not infringe privately owned rights. Reference herein to any specific commercial product, process, or service by trade name, trademark, manufacturer, or otherwise does not necessarily constitute or imply its endorsement, recommendation, or favoring by the United States Government or any agency thereof. The views and opinions of authors expressed herein do not necessarily state or reflect those of the United States Government or any agency thereof. 


\section{DISCLAIMER}

Portions of this document may be illegible in electronic image products. Images are produced from the best available original document. 


\section{TABLE OF CONTENTS}

PROGRAM OVERVIEW

SUMMARIES OF PROJECTS

GRANT AND LABORATORY PROGRAM

SMALL BUSINESS INNOVATION RESEARCH PROGRAM

APPENDICES

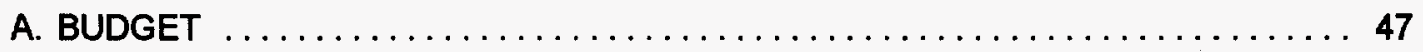

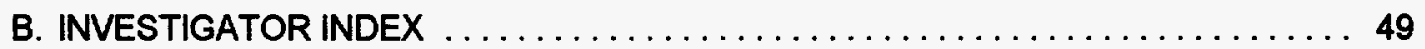

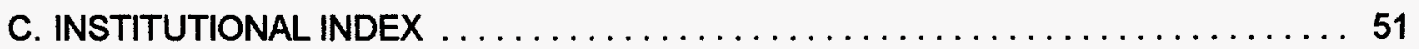

D. FACSIMILE COVER SHEET $\ldots \ldots \ldots \ldots \ldots \ldots \ldots \ldots \ldots \ldots \ldots \ldots \ldots \ldots \ldots \ldots \ldots$ 


\section{DIVISION OF ADVANCED ENERGY PROJECTS}

\section{PROGRAM OVERVIEW}

\section{CHARTER}

The mission of the Advanced Energy Projects Division (AEP) is to explore the scientific feasibility of novel energy-related concepts. These concepts are typically at an early stage of scientific development and, therefore, are premature for consideration by applied research or technology development programs. They may arise from advances in basic research or may be based on exploratory ideas that span multiple scientific and technical disciplines which do not readily fit into an existing DOE program area.

AEP does not support evolutionary research or large scale demonstration projects. The concepts supported can be characterized as high risk (in terms of scientific feasibility) and high payoff exploratory concepts. Research areas typically supported include physics, chemistry, materials, engineering, geosciences, biotechnologies and interdisciplinary projects.

\section{SCOPE}

The portfolio of projects is dynamic, but reflects the broad role of the Department in supporting research and development for improving the Nation's energy posture. Topical areas presently receiving support include:

- Alternative Energy Sources

- Innovative Concepts for Energy Conversion and Storage

- Alternate Pathways to Energy Efficiency

- Exploring Uses of New Scientific Discoveries

- Biologically-Based Energy Concepts

- Renewable and Biodegradable Materials

- Novel Materials for Energy Technology

- Innovative Approaches to Waste Treatment and Reduction

Infrequently, AEP supports scientific workshops to help identify promising energy areas needing research and concept feasibility testing. This interest does not elevate the particular workshop field above the other fields covered by AEP in terms of interest for funding.

\section{FUNDING}

Projects are supported for a specified period of time, which typically does not exceed three years. In Fiscal Year 1996, the average annual funding level for an AEP project was $\$ 250,000$ and the average funding period was slightly less than 36 months. Following AEP support, it is expected that each concept will be sufficiently developed and promising to attract further funding from other sources in order to realize its full potential.

\section{SUBMISSION GUIDELINES}

Projects supported by the Division arise from unsolicited ideas submitted by researchers. Unsolicited proposals can be submitted by universities, industrial organizations, non-profit research institutions, or private individuals. The Division also considers ideas or concepts submitted by researchers at national laboratories.

\section{PREPROPOSALS}

Before a formal proposal is prepared, the proposer should submit a summary (3-5 pages) of the proposed work to the Division for consideration. The summary should outline the scientific concept to enable an informed 
decision as to whether the proposed work would be programmatically suited to the charter of the Advanced Energy Projects Division. It should include concise descriptions of the proposed method and its potential benefit to energy science and technology. The summary should also contain estimates of the funding period and of the annual funding level. If possible, some discussion of anticipated follow-on funding scenarios should be provided. Elaborate preproposals exceeding five pages are not encouraged.

\section{PROPOSALS}

After an AEP programmatic interest has been established, a proposal must be submitted consistent with the guidelines specified in the document, DOE/ER-0249, "Application Guide for the Office of Energy Research Financial Assistance Program - 10 CFR Part 605, Issuance No. 3.1" In addition to these requirements, a 200300 word abstract describing the project should be included in the proposal.

\section{PROPOSAL EVALUATION}

Awards are based on the results of an evaluation process that includes independent reviews by external scientific and technical experts. The review process is the same for all submissions. Regardless of the outcome of the evaluation, proposers receive copies of reviewers' reports.

Questions asked of the reviewers depend on the subject of the proposal, but usually include the following:

1. What is the scientific and technical merit of the proposed effort?

2. Is the proposed effort innovative? How does it compare with other work?

3. Are there basic flaws or major shortcomings in the scientific or technical arguments underlying the concept?

4. Are the technological and/or material requirements associated with the proposed concept within present or near term capabilities?

5. Is there anything about the concept that makes its economics manifestly untenable, even under reasonably optimistic assumptions?

6. Is the anticipated benefit to the public high enough to warrant the Department of Energy's involvement in the R\&D effort?

7. How well does the proposed research match the AEP charter? 


\section{CONTACTS IN AEP}

- Dr. Walter M. Polansky, Director

- Dr. Maryka H. Bhattacharyya*

- Dr. Gesina C. Carter

- Dr. James C. Cunnane*

- Ms. Sue Ellen Stottlemyer

Advanced Energy Projects Division

U.S. Department of Energy

ER-33, GTN

19901 Germantown Road

Germantown, MD 20874-1290

Phone: $\quad 301 / 903-5995$

Fax: $\quad 301 / 903-6067$ (no more than 10 pages; also see Appendix D)

E-mail: walt.polansky@OER.DOE.GOV cynthia.carter@OER.DOE.GOV james.cunnane@OER.DOE.GOV sue-ellen.stottlemyer@OER.DOE.GOV

*On detail from Argonne National Laboratory

This book was compiled by Sue Ellen Stottlemyer.

This document also appears on the World Wide Web at http://www.er.doe.gov/production/octr/aep/aephome.html 


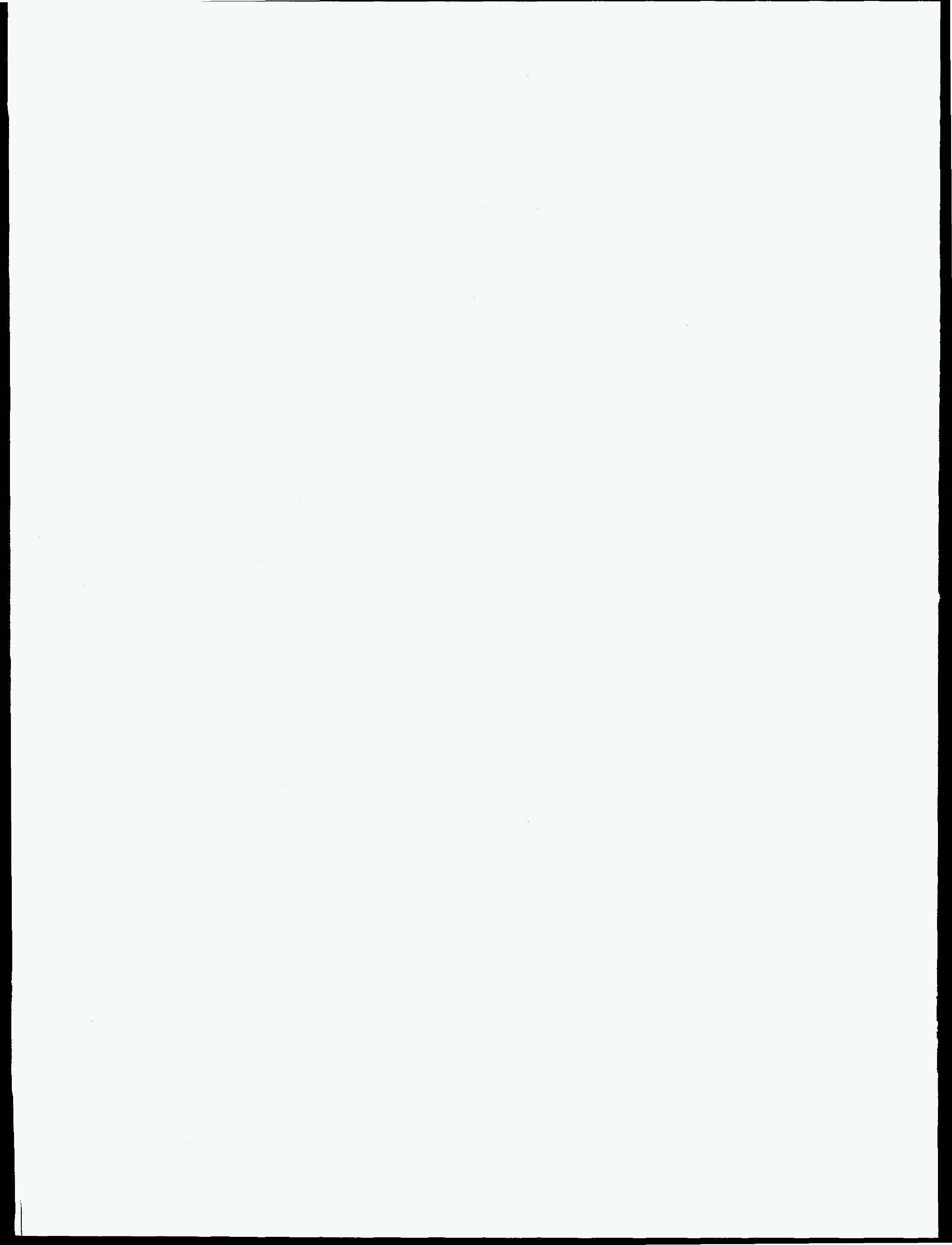




\section{SUMMARIES OF PROJECTS ACTIVE IN FY 1996}

\section{GRANT AND LABORATORY PROGRAMS}

There were 52 research projects in the Division of Advanced Energy Projects during Fiscal Year 1996 (October 1, 1995 - September 30, 1996). Eighteen projects were initiated during that fiscal year. See Appendix B for FY 1996 budget information. Further information on a specific project may be obtained by contacting the principal investigator. Note - To accommodate the limitations of the World Wide Web format, subscripts and superscripts are suppressed in the project summaries below.

\section{Alfred University \\ Alfred, NY 14802}

1. Combustion Synthesis and Engineering of Nanoparticles for Electronic, Structural and Superconductor Applications

Gregory C. Stangle

School of Ceramic Engineering

607/871-2798

Funding Profile

Date Started: November 1, 1992

Anticipated Duration: 42 Months

(Project Completed)*

FY $93-\$ 225,000$

FY $94-\$ 186,000$

FY 95 - $\$ 196,000$

Ultrafine particles are currently difficult to produce in commercial quantities and to use in the development of dense materials with precisely controlled microstructures. The investigation will: 1) produce nanoparticles of multicomponent oxide ceramic materials by a combustion synthesis technique that is readily scaled up; 2 ) apply proven, in-house grain-boundary engineering methods to fine-tune microstructure evolution during densification; 3) use conventional and rapid sintering techniques to densify consolidated nanoparticle compacts; and 4) characterize the material at each stage. Expected results include: a) the synthesis of nanoparticles of complex composition for use in several applications (such as high temperature superconductivity, high surface toughness/high temperature materials, superparaelectric materials); b) the development and reduction to practice of a generic, widely applicable process; and c) the evaluation of the energy efficiency and commercialization potential of the process. The proposed study will be interdisciplinary, bringing together the areas of ceramic, electrical and chemical engineering, and will enlist three U.S.-based companies to aid in focusing the research toward the commercialization of successful research results.

*Includes 6 month no-cost extension

\section{American University \\ Washington, DC 20016-8058}

2. Accelerated Beta Decay for Disposal of Fission Fragment Wastes

Howard Reiss

Department of Physics

202/885-2749

Funding Profile

Date Started: June 15, 1996

Anticipated Duration: 2 Years

FY $96-\$ 123,000$

FY 97 - $\$ 99,000$

It is proposed to develop a detailed theory for the acceleration of the so-called "forbidden" (actually just strongly inhibited) beta decays exhibited by fission fragment wastes. These wastes constitute the bulk of the radioactivity of nuclear reactor waste products for about the first thousand years after removal from a reactor, so a significant acceleration of the decay rate by a low cost method would present major benefits. The acceleration scheme depends upon the observation that each degree of forbiddenness in beta decay causes an extension of half life by a factor of about 10(4), and arises from a violation of quantum selection rules in the decay process. These selection rules involve only angular momentum and intrinsic parity, and it is proposed to supply these by coupling of a low frequency electromagnetic field to the nucleus. No energy needs to be contributed by the field - the fission fragment already possesses the necessary energy, which it would emit relatively quickly were it able to satisfy the quantum selection rules. Under normal circumstances, it is not possible to 
couple effectively a long-wavelength field to the nucleus because of the severe mismatch in sizes. It can be shown, however, that a very intense field provides qualitatively different coupling than is apparent from the perturbative (weak-field) coupling. Specifically, perturbation theory predicts that the coupling depends on the ratio of the field nucleus interaction to a characteristic nuclear energy. It is impossible to achieve a significant value for this ratio with low frequency fields. By contrast, intense-field theory shows that the coupling depends on the ratio of the field-nucleus interaction energy to $h \omega$, where $\omega$ is the circular frequency of the external field. This last energy is far smaller than a nuclear energy, and a practicable value of the coupling ratio can be achieved.

\section{Ames Laboratory \\ lowa State University \\ Ames, IA 50011-3020}

\section{Magnetic Refrigeration for Sub-Room Temperature Cooling}

Karl A. Gschneidner, Jr.

Metallurgy and Ceramics Division

515/294-7931

\section{Funding Profile}

Date Started: April 15, 1994

Anticipated Duration: 3 Years

FY $94-\$ 360,000$

FY $95-\$ 304,000$

FY $96-\$ 310,000$

The design of a new type of near-room temperature magnetic refrigerator and the demonstration of its technical feasibility as an alternative refrigeration technology for energyintensive industrial and commercial refrigeration systems is under development. Large-scale $(>30$ kW) chlorofluorocarbon (CFC) vapor cycle refrigeration units in commercial facilities, such as deep-freezers in meat packing plants and display case chillers in supermarkets, represent a significant portion of the total U.S. electrical energy demand. The efficiency of existing refrigerators is considerably less than that of the ideal Carnot efficiency because of intrinsic limitations of the currently used vapor cycle process, especially in the compression and Joule-Thomson expansion parts of the cycle. In contrast, the magnetic refrigeration cycle has a very high intrinsic efficiency; the efficiency appears to be limited by

factors susceptible to control, such as non-ideal materials properties, parasitic heat transfer, and flow losses. Replacement of vapor cycle refrigerators with magnetic refrigerators offers a significant potential energy savings. In addition, magnetic refrigerators do not require any ozonedamaging CFCs or other volatile fluids that have a significant greenhouse effect, so their widespread use would reduce potential environmental hazards. The elimination of CFCs is also in compliance with federally mandated programs to reduce the risk to the ozone layer. There are two major aspects of this project. The first is a materials development task, which will be carried out by the Ames Laboratory in Ames, lowa. The second task involves the engineering aspects of designing, constructing, and demonstrating a sub-room temperature active magnetic regenerator magnetic refrigerator, which will be carried out at the Technology Center of the Astronautics Corporation of America, in Madison, Wisconsin.

Ames Laboratory
lowa State University
Ames, IA 50011-3020

4. Composite Magnetostrictive Materials for Advanced Automotive Magnetomechanical Sensors

David C. Jiles

Metallurgy and Ceramics Division

515/294-9685

\section{Funding Profile}

Date Started: September 15, 1996

Anticipated Duration: 3 Years

FY $96-\$ 101,000$

FY $97-\$ 449,000$

FY $98-\$ 270,000$

There is a well established need for torque sensors for a variety of applications in automobiles. Such sensors can be used for electronic control of the vehicle by monitoring steering and drive train torques. In this project, new highly magnetostrictive materials are being investigated for use in advanced steering systems. Such sensors will eliminate the need for maintaining a pressurized hydraulic power steering system and will improve fuel efficiency by $5 \%$. These sensors will need to meet stringent specifications such as the ability to operate over a range of temperatures between minus $40 \mathrm{C}$ and plus $85 \mathrm{C}$, be able to survive unexpected mechanical shocks of up to $500 \mathrm{~N}$ and 
operate under continual vibrational forces of $150 \mathrm{~N}$. In addition, the sensors must be able to sustain overload torques of 135 N.m without malfunctioning or significantly changing sensitivity over the normal operating range of $+/-10 \mathrm{~N} . \mathrm{m}$. Analysis of the relationship between the magnetomechanical effect (the change in magnetization with stress) and the magnetostriction (particularly the rate of change of strain with magnetic field) has shown that highly magnetostrictive materials with low anisotropy, and hence high permeability, form the most promosing class of materials from which to develop such high performance sensors. This project is therefore investigating the fabrication of composite materials consisting of the highly magnetostrictive material Terfenol-D in a high-strength matrix material, in order to meet the performance specifications for these torque sensors.

\section{Argonne National Laboratory 9700 South Cass Avenue Argonne, IL 60439-4831}

5. Iron-Sulfur Chemistry in Petroleum Production

Mark R. Antonio

Chemistry Division

630/252-9267

\section{Funding Profile}

Date Started: December 15, 1995

Anticipated Duration: 3 Years

FY $96-\$ 302,000$

FY $97-\$ 298,000$

FY $98-\$ 300,000$

It is our concept that fundamental knowledge about the subsurface reservoir chemistry of iron and sulfur can be exploited to improve U.S. oil production from souring reservoirs. To realize this concept, our proposed research and development focuses on three scientific-technological issues concerning biotic and abiotic ferruginous sulfides, Fe-S, that plague secondary (i.e., waterflood) oil recovery operations. These microbiologicallymediated and chemically-produced sulfides contribute to well fouling, a problem that can completely ruin the production of a reservoir. The first program thrust area concerns studies of their origins, and interrelationships of these sulfides under different conditions of temperature, $\mathrm{pH}$, salinity, pressure, concentrations of iron and hydrogen sulfide, in combination with the presence of sulfate reducing bacteria, SRB. To complement these studies, the second thrust area involves the characterization of the Fe-S species by use of a suite of spectroscopic and analytical techniques. The fundamental understanding of iron-sulfur chemistry to be gained from this integrated research plan will provide otherwise unavailable insights about the speciation of iron in produced waters, and essential information about well fouling in subsurface oil reservoir formations. The third thrust area concerns the development of Mössbauer spectroscopy for field measurement and identification of iron-bearing solids at the drill site. We also plan to design a rugged, transportable, Mössbauer instrument to acquire data that will provide definitive information about the iron speciation in the downhole environment. $A$ comprehensive knowledge of the exact chemical and physical state of iron in production zones and waters should enable the selection of appropriate and phase specific chemical treatment programs to effectively offset declines and increase oil production in U.S. fields. The use of such a field capability during production operations will facilitate the controlled exploitation of our national oil reserves. The success of this program is expected to represent a significant breakthrough in oil field technology that will result in higher enhanced oil recoveries at reduced cost.

\section{Argonne National Laboratory 9700 South Cass Avenue Argonne, IL 60439}

6. Photorefractive Liquid Crystals: New Materials for Energy-Efficient Imaging Technology

Gary P. Wiederrecht

Chemistry Division

630/252-6963

\section{Funding Profile}

Date Started: February 15, 1995

Anticipated Duration: 3 Years

FY $95-\$ 320,000$

FY $96-\$ 300,000$

FY $97-\$ 289,000$

This project will develop a new class of materials that will be used to produce energy-efficient image processing micro-devices. These materials will exploit the photorefractive effect, a light-induced change in the refractive index of a nonlinear optical material that results from photogeneration of a space charge field caused by directional charge transport over macroscopic distances within a solid. 
Both frequency and phase information contained in light that has passed through a distorting medium can be recovered noise-free using photorefractive materials. The only high quality photorefractive materials commercially available today are expensive single crystals of inorganic materials such as barium titanate. This project will develop a completely new approach that combines cheap, easily processed organic materials with a built-in method of achieving the solid state order necessary to achieve photorefractivity comparable to that seen in inorganic crystals. The new approach uses organic molecules that undergo a phase transition above ambient temperatures to a liquid crystalline phase. Self-ordering in the liquid crystalline phase, followed by cooling to an ordered molecular solid, will impart both good optical nonlinearity and directional photoconductivity to thin solid films of these materials. These solid films have the potential to possess greater photorefractive sensitivity and faster response times than any material developed to date. The liquid crystals will be based on easily oxidized, disc-shaped organic molecules that are known to have liquid crystalline phases. The specific materials will be derivatives of triphenylenes, coronenes, porphyrins, and phthalocyanines. These molecules can be used to achieve the macroscopic order and good photoinduced charge generation characteristics that are required of high quality photorefractive materials for application throughout the visible and near-infrared spectral regions. Intrinsically asymmetric, nonlinear optical molecules, e.g. a chiral p-nitroaniline derivative, will be attached to the disc-shaped molecules and oriented in the liquid crystalline phase so as to maximize the nonlinear susceptibility of the material. Optical studies on the resulting solids will be utilized to verify the existence of photorefractivity and to accurately characterize the materials. Several device applications will be demonstrated.

\section{University of Arizona \\ Tucson, AZ 85721}

7. Creation and Destruction of $C(60)$ and Other Fullerene Solids

Donald R. Huffman

Department of Physics

$520 / 621-4804$

Funding Profile

Date Started: March 1, 1993

Anticipated Duration: 42 Months

(Project Completed) ${ }^{\star}$
FY $93-\$ 302,000$

FY $94-\$ 301,000$

FY 95 - $\$ 302,000$

This work will focus on the creation and destruction of fullerenes, for the purposes of producing new materials of interest to the Department of Energy. It is now known that, besides the famous $C(60)$ molecule (buckminsterfullerene), hundreds of other fullerenes, with masses of up to 600 carbon atoms, are also synthesized in the KrätschmerHuffman process. The physics underlying the creation of the fullerenes is poorly understood and the major portion of this work will be a systematic study of the process. This will involve construction of a new, fully-instrumented smoke-chamber, that will be used in a methodical exploration of fullerene yield versus production conditions. Mass-spectral analysis will be an indispensable part of this study. As part of the work, an existing time-of-flight massspectrometer at the University of Arizona will be upgraded for optimum performance with fullerene samples. Recent reports of the successful seeding of CVD-grown diamond films using thin films of $\mathrm{C}(70)$, and of the room-temperature conversion of solid $C(60)$ into diamond powder via nonhydrostatic compression, indicate that some of the first important commercial applications of the fullerenes may involve their destruction as a means of synthesizing high-performance materials. The second major portion of this work will be a systematic study of the destruction and modification of the various fullerenes by chemical reaction, electromagnetic radiation, and electron bombardment. Transmission electron-microscopy (TEM) and electron-energy-loss spectroscopy (EELS) will be very valuable in analyzing the results of these destructive tests, and a portion of the proposed funding will support this work at a TEM / EELS facility located at the University of Arizona.

*Includes 6 month no-cost extension

\section{Auburn University}

Auburn University, AL 36849 8. Energy Related Applications of Selective Line
Emitters

M. Frank Rose

Space Power Institute

334/844-5894

Funding Profile

Date Started: December 1, 1994

Anticipated Duration: 3 Years 
FY $95-\$ 291,000$

FY $96-\$ 254,000$

FY 97 - $\$ 266,000$

Infrared heat sources are used extensively for many processes in industry. From initial work, it appears feasible to develop intense infrared sources based upon electronic transitions in compounds of the rare earths which tend to radiate efficiently at discrete wavelengths rather than a continuum. This work is aimed at conducting the basic and exploratory research which will allow the development of high intensity, discrete frequency infrared sources which are custom tailored to specific industrial processes. This will be accomplished by investigating and characterizing the emissive properties of the rare earths in inert forms such as oxides, borides, carbides, or nitrides. The Center for the Rare Earth Elements at the DOE Ames Research Laboratory will be used as the source of information for selection of suitable rare earth elements and compounds. Fibrous inert compounds of the rare earths will be formed as necessary. Oxide fibers can be formed by soaking activated carbon fibers in a suitable liquid compound of the rare earth, such as a nitrate of the material. Since activated carbon fibers can be greater than $70 \%$ porous, a substantial fraction of the liquid can be absorbed for suitable processing. The composite materials are formed into a paper with minor additions of cellulose using standard paper making technology. Subsequent heating in a reducing atmosphere removes the cellulose and carbon, and forms essentially a pure metallic shell, mimicking the size of the activated carbon precursor. The final dimensions of the rare earth oxide fiber are determined by the initial dimensions of the precursor material. Successful samples will also be characterized for strength, flexibility, and lifetime at temperature. Large area radiators for specific frequencies will be constructed and evaluated with the cooperation of an industrial affiliate.

\section{University of California, Los Angeles Los Angeles, CA 90024-1547}

9. Characterization of a High Power RF Plasma Dissociator for Processing Mixed Wastes

Alfred Y. Wong

Department of Physics and Astronomy 310/825-9531
Funding Profile

Date Started: November 1, 1996

Anticipated Duration: 3 Years

FY $96-\$ 300,000$

FY $97-\$ 300,000$

FY $98-\$ 300,000$

UCLA is investigating a plasma technology for partitioning and concentration of the heavy (radioactive) materials while simultaneously dissociating hazardous wastes. The central concept behind this technology is the combination of an inductively coupled plasma dissociator without internal electrodes and an electromagnetic plasma centrifuge. We are proposing an experimental program to characterize the scaling of our high power, high throughput, electrodeless rf plasma dissociator. Extensive survey of past work has resulted in a program to advance our current research device to one that could be combined with the centrifuge for experiments at the DOE Hanford site. The research consists of systematic gathering of key data on steady-state, high-density plasmas, produced at atmospheric pressure, using comprehensive physical and chemical diagnostic techniques. The observations will be analyzed within the context of disposing toxic, hazardous, and radioactive wastes. The scaling laws of plasma temperature and density with applied if power, size of the dissociator, carrier gas composition and pressure will be addressed. Through the use of laser interferometry, visible and infrared emission spectrometry, laser-induced fluorescence, local if field, density and temperature measurements with water cooled probes, and a fully computerized GCMS, the proposed studies will elucidate the science of plasma confinement by if fields and vortex flows and non-equilibrium thermodynamics. The present device already demonstrates the effective dissociation of gas, liquid and solid samples. What is needed is the understanding of how this is accomplished through an overview of performance data and computer modeling of particle dynamics during dissociation. A well-tested atmospheric ion and neutral chemistry code will aid this process. Our experiments will be designed and built based on our present operating $50 \mathrm{~kW}$ dissociator, a fully computer controlled device. The research program will culminate in the design specification for a well-understood, research/proof-of-principle quality, $100 \mathrm{~kW}$ level If plasma dissociator that can be interfaced with a plasma centrifuge currently being developed by UCLA and the DOE Hanford facility. This system will be tested with simulated mixed waste and can be transformed into a 
transportable waste disposer for localized (in laboratory) cleanup tasks. The project will interface with scientists at Hanford and Livermore.

\section{University of California, Santa Barbara Santa Barbara, CA 93103}

10. Photo-Induced Electron Transfer From a Conducting Polymer to Buckminsterfullerene: A Molecular Approach to High Efficiency Photovoltaic Cells

\section{Alan Heeger \\ Materials Department \\ 805/893-3184 \\ Funding Profile \\ FY $93-\$ 171,000$ \\ FY $94-\$ 283,000$ \\ FY $95-\$ 446,000$}

Date Started: August 15, 1993

Anticipated Duration: 3 Years (Project Completed)

The recently-discovered photoinduced electron transfer, with subpicosecond transfer rate, in composites of a conducting polymer, MEH-PPV, and a molecular acceptor, buckminsterfullerene, $C(60)$, opens a new direction and a new opportunity for photovoltaic research. Since the charge transfer takes place $\sim 1000$ times faster than the radiative and/or non-radiative decay of photoexicitations, the quantum efficiency for charge transfer and charge separation is near unity. Photoinduced electron transfer across the donoracceptor rectifying heterojunction offers potential for solar cell applications, using materials that exhibit a unique combination of properties: electronic and optical properties of semiconductors and metals in combination with the attractive mechanical properties and the processing advantages of polymers. The potential advantages of an all-polymer heterojunction solar cell include the following: low cost (literally fabricated from solution); large area; and flexible (components are polymers that can be solution cast onto polymer substrates). The goal of the proposed research is to build upon this novel molecular approach to photoinduced charge separation and charge transfer, with quantum efficiency approaching unity, and to create a research and development program that will enable the production of efficient, flexible, "plastic" solar cells that can be implemented in large areas.

\section{University of Colorado \\ Boulder, CO 80309-0347}

11. Controlled Production in Cellulases in Plants for Biomass Conversion

Kathleen J. Danna

Department of Molecular, Cellular, and Development Biology

303/429-8735

\section{Funding Profile}

Date Started: June 15, 1996

Anticipated Duration: 3 Years

FY $96-\$ 162,000$

FY 97 - \$157,000

FY 98 - $\$ 164,000$

Plant biomass, the most abundant renewable resource on earth, is a potential source of ethanol fuel, provided that the cellulose and hemicelluloses contained therein can be converted efficiently into fermentable saccharides for feedstock. The longterm objective of this proposal is to facilitate development of transgenic crop plants harboring cellulolytic enzymes that can be activated after harvest to produce a suitable, inexpensive feedstock. Using Arabidopsis thaliana for these pilot studies, we will generate transgenic plants that contain genes for an endoglucanase and an exocellobiohydrolase, both of which have high temperature optima. These thermostable enzymes are well suited for industrial applications, and their activities should be low at temperatures used for plant growth. Because we will provide each protein with a plant signal peptide fused to the amino terminus, the enzymes will accumulate in the apoplast, where they can be subsequently activated in vitro to degrade secondary and primary cell walls. If constitutive expression of these enzymes, under the control of the Cauliflower Mosaic Virus $35 \mathrm{~S}$ promoter, is deleterious, we will confine expression of the genes to late periods of plant development by means of a senescence induced promotor, SAG12. We will: determine the effects of cellulase expression on plant growth and development and on cell wall structure and strength; determine the tissue and subcellular localization of the enzymes and the time course of expression; and evaluate the effectiveness of the enzymes to degrade endogenous cellulose in vitro under optimal enzyme reaction conditions. 
University of Colorado

Boulder, CO 80309

12. Two-Dimensional Synthesis: Ultrathin Porous Membranes

Josef Michl

Department of Chemistry and Biochemistry

303/492-6519

Funding Profile

Date Started: December 1, 1993

Anticipated Duration: 3 Years

FY $94-\$ 300,000$

FY $95-\$ 300,000$

FY $96-\$ 300,000$

The objective of this research program is to synthesize and characterize an ultrathin fishnet-like sheet, suitable for application in molecular separations. This will be a new kind of heatresistant organic-inorganic solid with a regular repeating two-dimensional structure, containing openings of a predetermined size. The first step will be the synthesis of a tentacle-carrying pillar-like monomer with three arms opposite to the tentacled end. Next, its molecules will be constrained by strong adsorption of the tentacles to a liquid-liquid interface, oriented with the pillar perpendicular to the surface and the arms parallel to it, at a distance of a little less that 10 angstroms. In the subsequent step, the arms of the monomer molecules will be cross-linked in two dimensions into a sheet composed of a regular covalent hexagonal lattice parallel to the surface. The polymerization will be monitored in situ. The lateral dimensions of the sheet will be maximized by a search for optimum reaction conditions. Neighboring sheet segments will be stitched together with relatively flexible threads to yield a large macroscopic piece of ultrathin membrane. The tentacles will then be clipped off, permitting desorption and removal of the net-like membrane from the surface. The construction will be completed by additional crosslinking to form a second hexagonal lattice on the side that previously carried the tentacles. The two hexagonal nets will thus be bonded into a single sheet through pillars located at well separated trigonal connector centers. The sheet will be about 15 to 20 angstroms thick, and will contain openings with a diameter of about 20 angstroms. The structure will be characterized by the techniques of surface science and its separatory properties will be tested. This will complete the proof-of-concept part of the project. The experience gained in the project will be used to design a second generation membrane for an actual industrial separation process, taking advantage of the flexibility available in the choice of the size of the openings, which can be chosen anywhere from nearly zero to about 40 to 50 angstroms in diameter, and in the choice of chemical functionalities at the rim of the openings.

\section{Colorado State University \\ Fort Collins, CO 80523}

\section{A Novel Tandem Homojunction Solar Cell: An Advanced Technology for High Efficiency Photovoltaics}

\section{Bruce Parkinson \\ Department of Chemistry \\ 970/491-0504}

\section{Funding Profile}

Date Started: July 1, 1995

Anticipated Duration: 3 Years

FY $95-\$ 322,000$

FY 96 - $\$ 268,000$

FY $97-\$ 255,000$

A material for the construction of a solar cell must meet a number of criteria to be suitable for large scale photovoltaic applications. It must be made up of abundant elements, which are environmentally benign, and when combined into a crystal have suitable electronic properties. The required electronic properties include a bandgap in the 1.1-1.8 eV range, high absorption coefficients to minimize the amount of material required, and high mobilities of photogenerated carriers to facilitate the collection of these carriers. The semiconductor, $\mathrm{ZnSnP}(2)$, meets all of the above requirements. It is isoelectronic with the III- $V$ alloy In GaP(2), but has the advantage, for photovoltaic applications, of not containing expensive and rare group III elements. In addition, this material does not contain toxic heavy metals such as are found in CdTe and CulnSe(2)/CdS thin film solar cells. The absorption coefficient for this material is also very high. The bandgap of $\mathrm{ZnSnP}(2)$ has the additional interesting and useful property of ranging from 1.24 to $1.66 \mathrm{eV}$, depending on the preparation conditions. Bulk crystal growth techniques have not yielded high mobility $\mathrm{ZnSnP}(2)$ but there is no a priori reason that the electronic properties of these materials cannot be as good as III-V materials, since very high mobilities were only achieved in III-V's after the development of modern epitaxial growth techniques. State-of-the-art metalorganic molecular beam epitaxy (MOMBE) will be 
used to grow epitaxial layers of $\mathrm{ZnSnP}(2)$ on lattice matched GaAs substrates. Studies of the orderdisorder transition in the metal sublattice, using both optical and electrical techniques and especially solid state NMR to examine atomic scale local environments, will be conducted in order to find the conditions for preparing materials with various bandgap energies and to understand the basic chemistry and physics associated with this interesting order/disorder phase transition. When the conditions can be established for preparing a material of a given bandgap, a "tandem homojunction" solar cell will be fabricated by variation of growth conditions in the MOMBE chamber in the appropriate way. This device should show significant efficiency advantages over a single material device or tandem heterojunction devices where lattice mismatch produces recombination promoting interface states.

\section{Energy and Environmental Research Corp. 18 Mason Irvine, CA 92718}

\section{Advanced Steel Reheat Furnace Development and Demonstration}

Richard R. Koppang

714/859-8851

\section{Funding Profile}

Date Started: September 15, 1996

Anticipated Duration: 2 Years

\section{FY $96-\$ 255,000$}

The steel industry is coming under stricter air emission regulatory control as the 1990 Clean Air deadlines are approached. Some of the higher emitting furnaces found in the steel industry are reheat furnaces, typically firing at between 50 and $500 \mathrm{MMBtu} / \mathrm{hr}$ and annealing furnaces, typically firing at rates up to $100 \mathrm{MMBtu} / \mathrm{hr}$. These furnaces tend to be inefficient, converting only 45 to $60 \%$ of the fuel usefully. Typical fuels fired are process off-gases and natural gas. This project intends to develop and commercialize an advanced steel reheat furnace which concurrently reduces NOx emissions by $50 \%$ while improving energy efficiency and productivity by up to $20 \%$. The project will be conducted in three phases. In Phase I, a data base will be acquired on large, high temperature zoned furnaces found in the ceramics and steel service. Reference furnaces will be selected and rated for up to three appropriate applications. Computational modeling will be employed to parametrically estimate the efficiency benefits of the technology. In Phase II, design issues identified in Phase I will be systematically addressed and resolved through prototype component design and development. Pilot furnace tests and physical flow modeling will be performed as appropriate. In Phase III, a prototype system will be designed, constructed, and tested at a large, integrated steel mill. This grant covers all Phase I and part of Phase II of this project; Phase III will be funded by other sources.

\section{Florida International University University Park \\ Miami, FL 33199}

15. Association of N(2)-Fixing Cyanobacteria and Plants: Towards Novel Symbioses of Agricultural Importance

Miroslav F. Gantor

Department of Biological Sciences

305/348-2201

\section{Funding Profile}

Date Started: April 1, 1996

Anticipated Duration: 3 Years

FY $96-\$ 162,000$

FY $97-\$ 157,000$

FY $98-\$ 164,000$

The ever growing demand for nitrogenous fertilizers with their attendant energy cost and environmental complications, makes the alternative of biological $N(2)$-fixation increasingly attractive. Cyanobacteria comprise a significant portion of all $\mathrm{N}(2)$-fixing microorganisms. Many can form symbiotic associations with diverse plants and fungi, but no case is known of a productive association of a cyanobacterium with an agriculturally important plant. Recently, we have demonstrated the ability of certain cyanobacteria to form intimate associations with wheat and rice and to penetrate the tissue of these plants. We propose to extend this work by addressing the following questions: 1) What is the most efficient method of introducing cyanobacteria into wheat? 2) What is the fate, location, and metabolic activity of cyanobacteria upon introduction into plants? 3) What is the cyanobacterial contribution to the nitrogen budget of the plant? And 4) What is the range of plants capable of forming such association? The fate and metabolic activity of cyanobacteria incorporated into plants will be monitored by a novel DNA-based method we have 
developed and by using cyanobacteria genetically tagged with genes encoding luciferase, an enzyme that produces luminescence. Different techniques of introducing cyanobacteria into plants, such as penetration via root, via stomata, co-culture of plant calli with cyanobacteria, and creation of nodule-like structures of plants and their colonization with cyanobacteria, will be considered. Cyanobacterial contribution to plant nutrition will be determined by measuring plant nitrogen content and (15) N incorporation. The results of these experiments may provide insight as to the requirements for exploiting N(2)-fixing cyanobacteria in the field and the benefits that may be expected.

\section{General Electric Company \\ Schenectady, NY 12301-0008}

16. Evaporation Through Tungsten to Achieve High-Rate Vapor Phase Processing of Intermetallics

David W. Skelly

Corporate R\&D Center

$518 / 387-6534$

Funding Profile

Date Started: January 15, 1994

Anticipated Duration: 3 Years

FY $94-\$ 291,000$

FY 95 - $\$ 291,000$

FY $96-\$ 318,000$

The understanding of high-rate electron beam evaporation synthesis derived from this investigation will have significant impact on the ability to fabricate advanced designs of turbine blades, designs which cannot be produced by any state-of-the-art technology. Success in this program will make possible forming the complex cooling structure after the casting process, followed by a thin outer skin deposited by electron beam (EB) evaporation to create a double-wall. This structure combined with composite materials developed specifically for the EB process, will provide long term efficiency improvements and enhanced service life. High-rate EB evaporation processes are currently difficult to control for deposition of complex alloys and intermetallics: fluctuations in power level and beam position can lead to large fluctuations in deposition rate and deposit chemistry. Modification of current practice of EB processes has been found to enhance chemistry uniformity and deposition rates through the addition of tungsten to the evaporation pool to permit much higher pool temperatures and stable pool dynamics. The objective of this research is to define optimum operating conditions for achieving economic deposition of controlled-chemistry, controlled-thickness $\mathrm{Ni}$-base superalloys, NbTibase metallic materials, and high strength, high temperature intermetallic phases. The approach will be to: evaluate process stability during prolonged evaporation through a tungsten-rich liquid pool; measure the effect of tungsten concentration in the pool on the evaporation process; characterize the influence of electron beam scan rate and scan pattern on the deposit chemistry and deposition rate; characterize the influence of the source temperature profile on deposit chemistry and deposition rate; determine evaporation conditions for Ni-base alloys containing $\mathrm{Ta}$ and Mo; and extend the electron beam evaporation-through-tungsten processing to higher melting intermetallic phases and NbTi-base metals.

\section{University of lowa \\ lowa City, IA 52242-1219}

\section{Supported Molten Metal Catalysts. Development of a New Class of Catalysts}

Ravindra Datta

Department of Chemical and Biochemical Engineering

319/335-1395

Funding Profile

Date Started: January 1, 1996

Anticipated Duration: 3 Years

FY $96-\$ 316,000$

FY $97-\$ 322,000$

FY 98 - $\$ 240,000$

This project is concerned with the design and development of an entirely novel class of active and selective catalysts called supported moltenmetal catalysts, or SMMC, with a view to eventually replace some of the existing precious metal heterogeneous catalysts used in the production of fuels and chemicals. SMMC is based on supporting ultra-thin films of the relatively lowmelting, inexpensive, and abundant metals and semimetals, from groups la, Ilb, Illb, IVb, Vb, and $\mathrm{Vlb}$, of the periodic table, on porous refractory supports, much like supported microcrystallites of traditional solid catalysts. This technique, thus, provides orders of magnitude higher surface area than is obtainable in conventional reactors containing molten metals in pool form and also 
avoids corrosion. These have so far been the chief stumbling blocks in the use of molten metal catalysts despite their higher selectivity and lower susceptibility to deactivation. While the SMMC technique can be applied to a large variety of reactions, it is proposed to initially concentrate on dehydrogenation and reforming reactions due to their commercial significance. Thus, dehydrogenation of methylcyclohexane and decalin and reforming of methylcyclopentane are planned to be studied. These represent reactions of increasing complexity in catalytic reforming. The initial choice of catalyst are tellurium based catalysts including alloys, due to the very promising results obtained in preliminary screening experiments. Other catalytic formulations will also be tested. The activity, selectivity, and stability of the selected catalysts will be compared with the traditional Pt catalyst in differential packed-bed reactors. The commercial potential of the developed catalysts will be explored.

\section{Johns Hopkins University \\ Baltimore, MD 21218}

18. Ultrasonic and Dielectric Noninvasive Diagnostics for Sintering of Ceramic Composites

Moshe Rosen

Materials Science Department

410/516-8678

Funding Profile

Date Started: December 1, 1993

Anticipated Duration: 3 Years

FY $94-\$ 358,000$

FY $95-\$ 342,000$

FY $96-\$ 290,000$

The potential advantages of using microwaves to process ceramics have been recognized for more than three decades. However, only during the last several years, the scientific and engineering communities have experienced an outburst of research in this area. Nevertheless, a profound understanding of how materials interact with microwaves during sintering is still lacking. Measurement of the dielectric and mechanical properties of a material during microwave processing in real-time can provide the necessary theoretical and experimental insight into understanding this interaction that can subsequently be applied for the optimization of microwave processing of materials. In the course of this project, in situ, nonintrusive diagnostics for microwave sintering of ceramic materials will be developed. The essence of the project is a specially designed system for ultrasonic and dielectric probes to be integrated within the microwave furnace. The ultrasonic data can be ultimately related to the densification process during sintering of ceramics, while the dielectric characteristics are connected to the absorption mechanism of the microwave energy by the ceramic material. Acquisition of such data during sintering will shed light on the sintering kinetics and its mechanism and, consequently, provide an understanding of the optimal sintering conditions needed to achieve maximum densification and the desired material properties. Furthermore, such data can be instrumental in developing predictive models for microwave sintering of ceramic materials.

\section{Lawrence Berkeley National Laboratory Berkeley, CA 94720}

\section{Compact MeV Ion Implanter}

\author{
Simone Anders \\ Plasma Applications Group \\ 510/486-6745
}

\section{Funding Profile}

Date Started: February 15, 1994

Anticipated Duration: 3 Years

FY $94-\$ 294,000$

FY $95-\$ 319,000$

FY $96-\$ 298,000$

A new kind of $\mathrm{MeV}$ ion implanter will be developed, the distinguishing features of which will be its relatively small size and low cost. The heart of the device will be a novel kind of ion source by means of which high charge state ions will be produced, thereby allowing the production of high energy ion beams ( $1 \mathrm{MeV}$ and above), using only modest accelerating voltages (one to several hundred kV). The ion source will be a repetitively pulsed vacuum spark source, and the implantation facility will thus also generate repetitively pulsed, large area, metal ion beams. By virtue of the relatively low voltages employed the implanter will be much more compact and of much lower cost than present state-of-the-art facilities that employ singly charged ions and megavolt power supplies. From the perspective of new physics, a novel kind of ion source will be developed - vacuum arc ion sources have been developed but not vacuum spark ion 
sources, and it is in the latter that the highly stripped ions are to be found, yielding high energy at modest voltage. From the perspective of new technology, this is an entirely new approach to doing $\mathrm{MeV}$ ion implantation, making high energy surface modification techniques feasible for a vastly broader field of users than at present.

\section{Lawrence Berkeley National Laboratory Berkeley, CA 94720}

\section{Blue-Emitting Devices Based on Gallium Nitride}

\author{
Michael D. Rubin \\ Energy and Environment Division \\ 510/486-7124
}

\section{Funding Profile}

Date Started: May 15, 1994

Anticipated Duration: 3 Years

FY $94-\$ 319,000$

FY $95-\$ 340,000$

FY $96-\$ 332,000$

The purpose of this project is to convert the recent breakthroughs in growth of gallium nitride ( $\mathrm{GaN}$ ) into practical ultraviolet and blue light emitting diodes and lasers. This technology is critical to national competitiveness in the development of the next generation of optoelectronic devices. Shortwavelength semiconductor devices based on $\mathrm{GaN}$ are needed for many important applications such as energy-efficient illumination, high-density optical data storage, flat-screen color displays, underwater communications, and high-temperature electronics. GaN is a III-V semiconductor with a direct bandgap of $3.4 \mathrm{eV}$ in the ultraviolet. One of the principal technical problems that limits device applications has been achieving controllable properties with addition of $\mathrm{Mg}$. The nitrogen concentration of the films was greatly increased, by using a reactive ionbeam process, thus eliminating the primary background defect concentration. Upon attaining threshold levels of conductivity and mobility, it was discovered that good quality material could be readily obtained by a variety of doping methods including ion implantation, diffusion and coevaporation of $\mathrm{Mg}$. The defect studies which guide the improvements in the growth process will be continued. This process, along with specialized ion beam technology, will be transferred to HewlettPackard where it will be reproduced in a largescale commercial growth system. Simultaneously, fabrication of light-emitting devices will begin, using current materials, in cooperation with HewlettPackard.

\section{Lawrence Berkeley National Laboratory Berkeley, CA 94720}
21. Combinatorial Synthesis of High Tc Superconductors

X. D. Xiang

Materials Science Division

510/486-6640

Funding Profile

Date Started: March 15, 1996

Anticipated Duration: 3 Years

FY $96-\$ 144,000$

FY $97-\$ 250,000$

FY $98-\$ 250,000$

FY $99-\$ 106,000$

Currently, there is a tremendous interest in materials such as high temperature superconductors, organic conductors, permanent magnets, nonlinear optical materials and zeolites. However, even through the properties of such materials have been extensively investigated, few general principles have emerged that allow one to predict the structures of new materials with enhanced properties. Consequently, the discovery of such materials remains a time consuming and rather unpredictable trial and error process made even more difficult by the increasing complexity of modern materials. The question arises whether there is a more efficient and systematic approach to search through the largely unexplored universe of ternary, quartenary, and higher order solid state compounds, in order to discover materials with novel electronic, optical, magnetic or mechanical properties. We propose to develop a new approach to materials discovery that will significantly increase the rate at which novel materials are discovered as well as increase our ability to correlate physical properties with structure. Specifically, we will develop the ability to rapidly synthesize and analyze large libraries, or collections, of solid state materials for specific electronic, magnetic, optical and structural properties. The aim of this project is twofold: 1 ) to develop the technology to the point where it can be used effectively for materials discovery; and 2) to apply the technology to the discovery of new superconducting materials. 
Lawrence Livermore National Laboratory Livermore, CA 94550

22. Solid State Multi-Layered Batteries

Richard M. Bionta

510/423-4846

Funding Profile

Date Started: October 15, 1993

Anticipated Duration: 2 Years (Project Completed)

FY 94 - $\$ 419,000$

FY 95 - $\$ 296,000$

The purpose of this project is to develop and study thin film solid-electrolyte batteries fabricated by the advanced multilayer sputtering techniques developed for $\mathbf{x}$-ray optics. This technique allows the battery to be constructed in situ by depositing the anode, electrolyte, and cathode as distinct layers with several computer controlled magnetron sputtering sources. Solid-electrolyte batteries have long been attractive because of their shelf-life and compatibility with severe environments. The discovery of new materials for cell construction has resulted in increased solid state battery research. Recently, rechargeable lithium cells that operate at ambient temperature have been developed based on ionically conducting solid polymer electrolytes. This project will concentrate on the development of thin-film solid-electrolyte cells constructed of lithium based inorganic materials fabricated by multilayer sputtering. The ability of this fabrication technique to discretely layer or compositionally grade thin films provides a unique opportunity to investigate the effect of electrode-electrolyte interface structure on cell performance. Finally, the computer control associated with this fabrication technique will allow the deposition of multiple cells in a bipolar configuration with either series or parallel connection. It is anticipated that this research will directly lead to practical applications of thin film solid state batteries as integrated power sources for modern electronic circuits (i.e. microsensors, memory elements, displays, and timers).

\section{Lawrence Livermore National Laboratory Livermore, CA 94550}

23. Thermoelectric Quantum Wells

Joseph C. Farmer

510/423-6574
Funding Profile

Date Started: January 15, 1994

Anticipated Duration: 3 Years

FY $94-\$ 350,000$

FY $95-\$ 350,000$

FY $96-\$ 350,000$

Solid state thermoelectric devices have no moving parts and can be used to convert heat directly into electricity. Such devices can also be used as chlorofluorocarbon (CFC)-free refrigerators, provided that an external voltage is applied. Unfortunately, thermoelectric devices are not as efficient as their mechanical counterparts. However, theoretical physicists at the Massachusetts Institute of Technology have recently used quantum mechanics to design a new class of thermoelectric materials that may improve the efficiency (figure of merit) of thermoelectric devices to a point where they are competitive with conventional internal combustion engines and CFC-based refrigerators. Process technology developed at Lawrence Livermore National Laboratory for the fabrication of $x$-ray optics is now being used to synthesize these new multilayer thermoelectric thin films. Multilayers are being made by alternately sputtering quantum well and barrier layers onto a moving substrate from dual magnetrons. A number of multilayer films, including high-temperature $\mathrm{Si}(0.8) \mathrm{Ge}(0.2) / \mathrm{Si}$ and low-temperature $\mathrm{Bi}(0.9) \mathrm{Sb}(0.1) / \mathrm{PbTe}(0.8) \mathrm{Se}(0.2)$, are being synthesized and evaluated. This research can lead to new materials and devices.

\section{Lawrence Livermore National Laboratory Livermore, CA 94550}
24. Porous Carbons: Controlling Structure, Composition and Performance

Tri D. Tran

Chemistry and Materials Science Department 510/422-0152

Funding Profile

Date Started: March 15, 1994

Anticipated Duration: 3 Years

FY $94-\$ 335,000$

FY $95-\$ 355,000$

FY $96-\$ 374,000$

This research examines the synthesis and processing conditions necessary to tailor the local structure and composition of porous carbons for 
potential applications in energy storage devices (i.e., batteries, capacitors). Carbon aerogels are being formed from resorcinol-formaldehyde and phenolic-furfural precursors. These porous carbons have low electrical resistivity, an ultrafine pore size distribution, high surface area (400 to 1100 square meters per gram, roughly the size of one or two basketball courts), and a solid matrix composed of interconnected particles or fibers. Preliminary data show that these materials are attractive electrodes for double layer capacitors. Carbon foams derived from the phase separation of polyacrylonitrile/solvent mixtures are being investigated as lithium intercalation anodes for rechargeable lithium-ion batteries. These carbon foams differ from aerogels in that they have much larger pore sizes and one or two orders of magnitude lower surface area. High capacity and good cycleability are observed during lithium intercalation experiments. These materials can potentially lead to new batteries with energy densities that are approximately four times greater than conventional nickel-cadmium batteries. In summary, this research project investigates sol-gel polymerization of multifunctional organic monomers, the phase separation of polymer/solvent mixtures, the formation of porous composites, intrinsic chemical doping, and pyrolysis in controlled atmospheres. A variety of characterization tools are being used to study the structure and properties of porous carbons. The overall objective is to develop a fundamental understanding of how morphology, chemical composition, and local order affect the electrochemical performance of porous carbons. The potential payoff from this research is the development of new energy storage devices with superior performance.

\section{Los Alamos National Laboratory Los Alamos, NM 87545}

25. Conversion of Atmospheric and Effluent Carbon Dioxide to Methanol via High Temperature Photolysis

Reed J. Jensen

505/667-9909

Funding Profile

Date Started: May 15, 1995

Anticipated Duration: 3 Years

FY $95-\$ 200,000$

FY $96-\$ 300,000$

FY $97-\$ 250,000$
The purpose of this project is to gather data to support an evaluation of a proposed process for the conversion of atmospheric and effluent $\mathrm{CO}(2)$ to methanol via high temperature, solar photolysis. The underlying principle is that once $\mathrm{CO}(2)$ is converted to $\mathrm{CO}$, it is a simple matter to convert it to methanol. Recent work in Europe has shown the existence of previously unknown, bent, excited states of $\mathrm{CO}(2)$. It is now evident that any form of vibrational energy enables the transition to these states through symmetry effects and enhanced Frank-Condon factors. The states lie much lower than the well known dissociative states near $9 \mathrm{eV}$. The absorption cross sections for transitions to these states will be measured at temperatures up to $2800 \mathrm{~K}$. The approach is to employ an existing hot gas cell to measure light absorption and oxygen production. A laser system will provide violet and blue wavelengths important to the central idea of this proposal. Favorable basic data from these measurements could lead to an effective process for reducing atmospheric $\mathrm{CO}(2)$ and decreasing oil imports.

\section{Los Alamos National Laboratory Los Alamos, NM 87545}

\section{Seismic Stimulation of Oil Production in Depleted Reservoirs}

Paul Johnson

GeoEngineering Group

505/667-8936

Funding Profile

Date Started: December 15, 1995

Anticipated Duration: 3 Years

FY $96-\$ 300,000$

FY $97-\$ 300,000$

FY $98-\$ 300,000$

In this project, we propose to conduct research on an unproven method for increasing energy production and economy: the stimulation of oil reservoirs by seismic waves. We propose to identify and quantify the importance of critical experimental variables that can enhance oil production in the presence of elastic wave stimulation. Our work will proceed in two stages: exploratory R\&D and field demonstration. In the first stage, we will perform scaled laboratory experiments on typical formation rocks. We will determine wavefield parameters that cause changes in relative permeability of oil for different oil-to-water ratios and changes in residual oil 
saturation for simulated waterflood tests. We will also perform theoretical modeling and laboratory experiments as needed to study physical mechanisms for flow enhancement due to wave stimulation. In the second stage of work, we will collaborate with four major oil companies, Texaco, Marathon, Amoco and Phillips Petroleum, to perform stimulation tests in oil fields with well characterized physical properties and production histories. The laboratory and field tests will be partially supported by contributions from our industrial collaborators. Results of our laboratory and theoretical work will be used to design the field experiments. We intend to demonstrate the potential usefulness of wave stimulation techniques for enhancing oil production. Our work could provide strong incentives to the oil industry to further develop this technology for routine implementation in secondary recovery procedures.

\section{Los Alamos National Laboratory \\ Los Alamos, NM 87545}

\section{Magnetically Enhanced Thermoelectric Cooling}

Albert Migliori

Materials Science and Technology Division

505/667-2515

Funding Profile

Date Started: March 15, 1996

Anticipated Duration: 3 Years

FY $96-\$ 250,000$

FY $97-\$ 250,000$

FY $98-\$ 250,000$

Cryogenic solid-state refrigerators based on the Ettinghausen effect can provide vastly superior performance to Peltier devices, opening up new markets in electronics and in superconductor-, and medical applications. Surprisingly, this most effective of solid-state cryogenic refrigeration processes is not being studied at present. Yet it is much less restrictive in the possible materials that can be used, is simpler to construct (even noting that a small permanent magnet must produce a field at the device), and has already achieved lower temperatures than Peltier coolers, the only devices presently under investigation. Recent discoveries of new hybridization-gap semi-conductors and semi-metals, and the commercial availability of high-strength $\mathrm{Nd}(2) \mathrm{Fe}(14) \mathrm{B}$ permanent magnets, open the way for development of new ultra-highperformance, all solid-state Ettinghausen refigerators. We propose here to initiate studies of such coolers using modern materials and to engineer the world's best solid-state cryocooler.

\section{Los Alamos National Laboratory Los Alamos, NM 87545}

28. Synthesis and Properties of High Strength Nanolayered Composites

Michael Nastasi

505/667-7007

Funding Profile

Date Started: February 15, 1993

Anticipated Duration: 3 Years (Project Completed)

FY $93-\$ 150,000$

FY $94-\$ 315,000$

FY $95-\$ 330,000$

The objective of this project is to synthesize and evaluate ultra high strength vapor-deposited nanoscale materials both in the monolithic and composite form. Such materials have been shown to posses strengths that are within a factor of three or four of the theoretical shear strength modulus. Synthesis of nanoscale materials presents the opportunity to develop a basic understanding of the deformation and fracture mechanisms that operate close to the theoretical limit of strength of materials to enable a new technological breakthrough, namely mechanical miniaturization. The availability of the fine-scale ultra high strength materials would provide the basis for fabricating, among others, miniature activators, springs, and diaphragms, for biomedical or sensor applications. The primary performance task will be to synthesize ductile materials with ultra high strength for application in mechanical miniaturization.

Louisiana State University Baton Rouge, LA 70803-7303

29. Reducing Energy Consumption and Pollution in Plastic-Manufacturing Processes: Phase Behavior Roots of Fouling Phenomena that Cause Energy and Product Waste
M. Radosz
Department of Chemical Engineering
504/388-1426 
Funding Profile"**

Date Started: September 15, 1996

Anticipated Duration: 3 Years

FY $96-\$ 122,000$

FY $97-\$ 122,000$

FY $98-\$ 122,000$

The overall goal of the proposed research is to understand the phase behavior of ethylene copolymers in compressible fluid streams, such as copolymer solutions in supercritical and near critical fluids. Such understanding is needed to develop new plastic-manufacturing processes that are less energy intensive, and produce less pollution and less waste product. Specifically, such understanding is needed to be able to control undesirable phase transitions and, hence, eliminate the root cause of fouling phenomena in pipelines, reactors and separators. This is in contrast to mitigating the fouling consequences using specially treated surfaces and additives. The proposed approach is a synthesis of experiment and thermodynamic modeling. The experiments will be aimed at accurate phase transition data for wellcharacterized model polyolefin systems. The thermodynamic modeling will be aimed at predicting such phase transitions. The basis for this approach is a series of preliminary but promising experimental and computational results with an equation of state, referred to as the copolymer SAFT (statistical associating fluid theory). The copolymer SAFT should explicitly account for the effects of microstructure on the thermodynamic properties of copolymers. This has never been done before and will impact the way we characterize very large, structured molecules. The objectives proposed for this project will concern a specific system of ethylene copolymers and small olefins. The focus will be on the effect of branchiness (hence crystallinity) and molecular weight on the phase transitions that induce undesirable fouling phenomena.

**Budgets include funding from Basic Energy Sciences' Materials Sciences Division

\section{Massachusetts Institute of Technology} Cambridge, MA 02139

\section{Superconducting Bitter Magnets}

Leslie Bromberg

Plasma Fusion Center

617/253-6919
Funding Profile

Date Started: May 1, 1993

Anticipated Duration: 4 Years*

FY $93-\$ 300,000$

FY 94 - $\$ 300,000$

FY $95-\$ 300,000$

A novel process for manufacturing high temperature superconducting magnets using thickfilm superconducting material on structural plates is described. This technique is similar to that used in constructing Bitter magnets. The superconductor is manufactured in the required shape, avoiding the need to develop ductile wires. The structural metal plate serves as the material as well as the quench protector. A dielectric with high electrical resistivity is placed between the conductor and the metal plate (copper, aluminum, composite materials). This method can be utilized for manufacturing solenoidal, toroidal, saddle, and other types of magnets with both high-T(c) and low$T$ (c) superconductors. This project will address issues faced in this type of magnet construction (quench protection, materials compatibility, stability, and cooling). A theoretical program to gain understanding on these issues will be carried out. Experiments will be conducted to determine the feasibility of manufacturing magnets using this technique. Several methods for manufacturing the superconductor will be tested. Interaction with the manufacturers to improve the performance of superconducting materials for this application will be maintained. It is expected that in the final phase of this program, magnets will be constructed and tested. A team arrangement between the Plasma Fusion Center at the Massachusetts Institute of Technology (MIT) and the Superconductivity Technology Center at the Los Alamos National Laboratory (LANL) has been established.

*Includes 12 month no-cost extension 
University of Michigan*

Ann Arbor, MI 48109-2099

31. Tunable Femtosecond UV Light Source Using a Novel Frequency Upshift Technique

Henry C. Kapteyn

Center for Ultrafast Optical Science

313/763-0573

Funding Profile

Date Started: July 15, 1996

Anticipated Duration: 1 Year

FY $96-\$ 172,000^{* *}$

The goal of this project is to implement a new approach for producing ultrashort light pulses at ultraviolet to extreme-ultraviolet wavelengths. An intense light pulse can be used to create a moving ionization front; light can be reflected from this front and experience a relativistic Doppler upshift. Two recently-developed technologies now make it possible to create tunable light pulses of unprecedented short duration using this technique. First, the recent development of small-scale terawatt femtosecond laser systems makes it possible to create an extremely abrupt moving ionization front, using the process of multiphoton ionization. Second, recently-developed techniques have resulted in the generation of single-opticalcycle duration pulses in the far-infrared. It is shown herein that it is possible to upshift such pulses to optical and shorter wavelengths while still retaining nearly single-cycle duration. This way, pulses of 1-5 femtoseconds duration in the UV to XUV region of the spectrum can be created.

*This project was started on April 19, 1993, at Washington State University; it was transferred to the University of Michigan as a result of Professor Kapteyn's relocation.

**The total three-year funding for this project is $\$ 445,000$.

\section{University of Michigan \\ Ann Arbor, MI 48109}

32. Feasibility of a Novel Approach for Fast, Economical Determination of Radiation Damage in Nuclear Reactor Cores

Gary S. Was

Department of Nuclear Engineering

313/763-4675
Funding Profile

Date Started: November 1, 1992

Anticipated Duration: 4 Years*

FY $93-\$ 156,000$

FY $94-\$ 145,000$

FY 95 - $\$ 149,000$

The objective of this project is to determine the feasibility of using proton irradiation as a radiation damage tool, resulting in order-of-magnitude savings in time and cost over current methods to study radiation damage. The feasibility will be established through the application of proton irradiation to the determination of the mechanism of irradiation assisted stress corrosion cracking (IASCC) in light water reactors (LWRs). The technique is ideally suited to this major industry problem. The emphasis of the technical program will be on the role of grain boundary chemistry and microstructural changes on IASCC. High energy proton irradiation has recently been shown to produce grain boundary segregation of the major alloying elements and impurities, and a microstructure that is comparable to that produced by neutron irradiation in a fraction of the time and at a fraction of the cost. This program is designed to uncover the effects of grain boundary impurity segregation, chromium depletion, and the irradiated microstructure on ASK. It involves both experimental and computational efforts that have been developed in our laboratory. The plan also calls for investigation of the dose, dose rate, temperature and injected hydrogen effects and comparison with available neutron irradiation data. The combination of microstructure characterization with its dependence on critical irradiation parameters will provide both a better understanding of the role of irradiation in the mechanism, as well as an assessment of the feasibility of using proton irradiation to study neutron irradiation in LWR cores. Collaborations with industry and national laboratories have been established to exchange materials that will allow us to benchmark results of proton irradiation against neutron irradiation and to determine the irradiation conditions that produce the best match. Because the time and cost involved in these experiments is a small fraction of that required for neutron irradiation, the technique will provide a more cost-effective and time-efficient method of studying radiation change in core structures and in assessing new materials.

\footnotetext{
*Includes 12 month no-cost extension
} 
University of Minnesota

Minneapolis, MN 55455

\section{Injection Molding of Plastics from Agricultural Materials}

Mrinal Bhattacharya

Department of Agricultural Engineering

612/625-5234

\section{Funding Profile}

Date Started: January 1, 1996

Anticipated Duration: 3 Years

FY 96 - $\$ 166,000$

FY $97-\$ 169,000$

FY $98-\$ 172,000$

In the last few years there has been a renewed interest in the development of materials that mimic plastics and have a significant component of agricultural commodities. For example, these materials could be a blend of starch and/or protein and a synthetic polymer. The goal for such materials is two-fold. First, the materials can be processed into end products having acceptable physical and chemical properties pertaining to their end use. Second, increased environmental friendliness of the product may open an avenue for increased usage of farm commodities and other renewable resources. The presence of the synthetic polymer is needed to impart desirable physical properties, for example, insensitivity to moisture, or tensile- and impact strength. While the biodegradability of the product depends on the degradability of the synthetic material, the presence of a large agricultural component in the blend $(60$ to $70 \%$ or more) is expected to reduce the environmental impact of 'plastic' material. Moreover, the increased use of an agricultural component is expected to add significant value to the large surplus of farm commodities that currently exists in the United States. The processing of blends of these materials remains a largely unexplored area. Most plastic parts are produced by extruding and then injection molding. Injection molding, a widely used method of polymer processing, is characterized by high production rates and accurately sized products. Yet, other than in terse citations in patents, injection molding of starch-based plastics has not been discussed in the scientific literature. A thorough understanding of the molding process is necessary to produce products of the required quality at the lowest possible cost. Furthermore, the fact that we are concerned with a blend (as opposed to a homopolymer) complicates matters significantly.
The presence of weld lines in injection-molded articles made from homopolymers is known to limit the use of plastic materials. This problem is compounded in the case of polymer blends. During the flow process, a polymeric material undergoes simultaneous mechanical and thermal influences and changes of state. Also, depending on the morphology, the flow process will introduce orientation, residual stresses, and shrinkage in injection-molded products that affect the physical properties and dimensional stability of the finished products.

\section{National Renewable Energy Laboratory 1617 Cole Boulevard Golden, CO 80401-3393}

\section{PV-Powered, Electrochromic Windows}

David K. Benson

Basic Sciences Division

303/384-6462

\section{Funding Profile}

Date Started: February 15, 1994

Anticipated Duration: 3 Years

FY $94-\$ 330,000$

FY $95-\$ 330,000$

FY $96-\$ 330,000$

This project will develop a retrofit window treatment for architectural windows. The window treatment will be a combination of thin-film photovoltaic cells and an electrochromic coating, both deposited onto a flexible polymer film. The coated polymer film will be applied to the interior surfaces of existing building windows and used to modulate the solar transmittance into the building thereby providing automatic solar-gain control and daylighting control functions which will reduce heating, cooling, and lighting energy usage in the building. The selfpowered window obviates the need for costly electrical wiring. This kind of "smart" window covering has the potential to balance the performance of the window, giving it a net energy benefit. It has been predicted to be able to reduce the cooling power demand of a south-facing window in a climate such as southern California by about $40 \%$ and to have similar benefits in other locations. A large fraction of the billion square meters of existing building windows in the U.S. could benefit from this kind of treatment. At present, an estimated 1 to $1.5 \%$ of the total cooling energy need in buildings and 10 to $30 \%$ of the peak electric utility power demand is caused by windows 
amounting to about a $1500 \mathrm{MW}$ increase in electric utility peak electric power demand each year due to new windows at a national operating cost of about $\$ 10$ billion. New photovoltaic and electrochromic coating designs and new processes for their deposition onto flexible polymer substrates will be developed in this project.

\section{National Renewable Energy Laboratory 1617 Cole Boulevard \\ Golden, CO 80401-3393}

\section{Hot Carrier Solar Cells}

Mark C. Hanna

Basic Sciences Division

303/384-6620

\section{Funding Profile}

Date Started: February 15, 1994

Anticipated Duration: 3 Years

FY $94-\$ 330,000$

FY $95-\$ 330,000$

FY 96 - $\$ 330,000$

This project is focused on the development and understanding of a new kind of high efficiency solar cell, called a Hot Carrier Solar Cell (HCSC), which may have the potential to double the maximum efficiency of conventional solar cells. The ultimate thermodynamic conversion efficiency of an optimized HCSC is $66 \%$, compared to $31 \%$ for an optimized conventional single bandgap solar cell. This project explores a new approach for increasing the efficiency of solar cells by attempting to utilize the excess kinetic energy of higher energy (hot) carriers generated by the absorption of high energy photons in the solar spectrum. Normally, the excess kinetic energy of hot carriers created by absorption of solar photons in photovoltaic cells is converted to heat and is thus unavailable for useful work. The HCSC employs a new type of semiconductor structure (called a superlattice) to absorb the solar photons and to inhibit hot carriers from cooling in the photovoltaic device. Bandgap engineering techniques will be used to control important physical properties of the superlattice, such as the hot carrier energy loss rate, hot carrier mobility, and the absorption threshold. Hot carriers from the superlattice region are collected in high bandgap contacts to produce a higher photovoltage. With this combination, the photocurrent and photovoltage of the cell can be separately controlled and optimized, unlike the conventional p-n photovoltaic cell where the photocurrent and photovoltage are coupled. The HCSC is fabricated from Group III-V semiconductor compounds and alloys grown by low pressure organometallic chemical vapor deposition. This project will synthesize HCSCs, measure their performance and properties, compare them to appropriate conventional solar cells, and develop a theoretical model for predicting the device characteristics of the HCSC.

\section{National Renewable Energy Laboratory 1617 Cole Boulevard \\ Golden, CO 80401-3393}

36. Atomic and Nanoscale Engineering of Thermophotovoltaic Semiconductors Using Scanning Probe Microscopy Techniques

Lawrence L. Kazmerski

Photovoltaics and Basic Sciences Division 303/384-6600

Funding Profile

Date Started: July 10, 1994

Anticipated Duration: 3 Years

FY $94-\$ 177,000$

FY $95-\$ 552,000$

FY $96-\$ 315,000$

This project uses scanning probe microscopies for the atomic-scale engineering of semiconductors leading to advances in understanding their improvement, and their use in energy-conversion thermophotovoltaic (TPV) structures and devices - cells designed to produce electricity from surfaces emitting radiation in the 1400 to $2000 \mathrm{~K}$ range. This program consists of three interrelated segments: 1) preparation of selected GalnAs and GalnAsP alloy surfaces having suitable compositions; 2) use of modern electronic structure theory to predict the properties of these semiconductor surfaces before and after atomicscale engineering takes place and to provide guidance for the experiments; and, the central and primary activity, 3 ) evolution of the novel atomic processing microscope to image, process (including atom removal and placement), and characterize these semiconductors with the same nanoscale spatial resolutions and to produce nanometer-scale optimized TPV structures for the next generation of these energy conversion devices. These atomic-scale investigations involve the manipulation of atoms in order to study the fundamental defect properties that limit both materials properties and device performance. The 
program provides the first atomic engineering directed toward these III-V materials. It further provides fundamental information of the nature of defects, their electrooptical properties and the ability to electronically heal them with intrinsic and extrinsic atomic species. This project links events on the atomic scale to the current understanding of semiconductor surface and interface physics. The project provides first-time characterization of the electrooptical properties of TPV semiconductors in compositional ranges not previously investigated. This information is used to demonstrate optimized next-generation TPV structures that will lead to highly efficient cells for energy applications.

\section{National Renewable Energy Laboratory 1617 Cole Boulevard Golden, CO 80401-3393}

\section{Photochemical Solar Cells}

Arthur J. Nozik

303/384-6603

Funding Profile

Date Started: January 15, 1995

Anticipated Duration: 3 Years

FY $95-\$ 150,000$

FY $96-\$ 150,000$

FY $97-\$ 150,000$

Very high power conversion efficiencies (8-12\%) for photochemical solar cells were reported in 1991. These solar cells consist of highly porous nanocrystalline films of $T i O(2)$ (band gap $=3.0 \mathrm{eV}$ ) that are sensitized to the visible region of the solar spectrum through adsorption of Ru-containing metal-organic dye complexes on the TiO(2) particle surface. This represents more than two orders of magnitude improvement in the power conversion efficiency of dye-sensitized semiconductor electrodes in a photochemical cell. A dyesensitized photochemical solar cell system based on TiO(2) powders is very attractive from the point of view of potential low cost and high semiconductor photostability. This project is an integrated program of basic and applied development research that is funded jointly by three U.S. Department of Energy program offices: the Division of Chemical Sciences in the Office of Basic Energy Sciences, the Photovoltaic program in the Office of Utility Technology and Advanced Energy Projects. In addition to the molecular dyesensitized TiO(2) system, research is also occurring to study other organic heterojunctions with wide bandgap semiconductors for photovoltaic applications. The AEP portion of the project is to develop a configuration where the system is able to efficiently split water into hydrogen and oxygen, rather than to produce electricity. An inexpensive source of solar-produced hydrogen would be greatly beneficial to the energy economy of the world, and would result in the use of hydrogen as a non-polluting substitute for many of the fuels currently in use.

\section{University of Nebraska \\ Lincoln, NE 68588-0111}

\section{Fabrication and Characterization of Micron Scale Ferromagnetic Features}

Peter A. Dowben

Department of Physics

402/472-9838

Funding Profile

Date Started: July 15, 1995

Anticipated Duration: 3 Years

FY $95-\$ 133,000$

FY $96-\$ 101,000$

FY $97-\$ 106,000$

This is a project to study micro scale features of ferromagnetic nickel, cobalt, cobalt-palladium alloys and cobalt-palladium heterostructures fabricated by "direct writing," i.e. by selective area deposition from organometallic compounds. There are two goals for this research program. First, by making magnetic features smaller and smaller, in a variety of different shapes, the project will elucidate the influence of defects on magnetization reversal and coercivity. Second, the project will determine if there is any coupling between small ferromagnetic features (approx. 1 micron), possibly substrate mediated, on the length scale of 1000 angstroms smaller. This research program is based upon conventional methods for imaging magnetic domains. Polarized light microscopy permits not only imaging micron scale features but also determination of the magnetic orientation and coercivity with some spacial resolution. A microscope will be used to make polar Kerr rotation measurements and obtain spaciallyselective magnetic information. A unique capability for probing the electronic structure of our magnetic features at resonance: spin polarized inverse photoemission with both longitudinal and transverse spin polarization will also be used. Essential to this project is a new technique for 
fabricating micro-scale ferromagnetic features. Organometallic chemical vapor deposition techniques sufficient to deposit pure metal features with excellent spacial resolution have been developed at this laboratory. These techniques allow selective deposition of large uniform arrays of nickel, cobalt, cobalt-palladium alloys and cobaltpalladium heterostructures in features as small as 0.2 microns, and as thin as a few monolayers or as thick as 10 microns. Multilayers can be made by the successive deposition of different metals or alloys by the sequential photolysis of different organometallic source compounds. While unconventional in many respects, this program utilizes a technology that is compatible with the fabrication of metal features 100 angstroms across in one Scanning-Tunneling microscopy run. The approach is superior to techniques employing ion beams or conventional lithography and is inexpensive and compatible with the fabrication of the next generation of optical and magnetic recording media.

\section{Oak Ridge National Laboratory \\ P.O. Box 2008 \\ Oak Ridge, TN 37831}

\section{Biomolecular Optoelectronic Devices}

Elias Greenbaum

423/574-6835

Funding Profile

Date Started: January 15, 1996

Anticipated Duration: 3 Years

FY $96-\$ 370,000$

FY $97-\$ 350,000$

FY $98-\$ 300,000$

The key purpose of this research is acceleration of practical device development based on original Oak Ridge National Laboratory proof-of-principle scientific discoveries which were supported by the Division of Chemical Sciences, Office of Basic Energy Sciences. It is motivated by knowledge of the intrinsic photophysical properties of the reaction centers of photosynthesis: nanometer dimensions, picosecond response times, and the ability to generate potential differences of about 1 volt upon absorption of a photon. The proposed research project is based on original discoveries in molecular electronics made at Oak Ridge National Laboratory. These include: 1) first demonstration of direct electrical contact with the electron transport chain of photosynthesis; 2) photoflash deposition of metallic platinum at the site of electron emergence from the Photosystem I reaction center of photosynthesis; 3) establishment of a novel platinization "welding" technique that allows construction of two-dimensional arrays of Photosystem I reaction centers on a metal surface; 4) first demonstration of a biomolecular diode in a single isolated photosynthetic reaction center; and 5) first demonstration of the compatibility of metallic platinum with the functionality of isolated Photosystem I reaction centers.

\section{Ohio State University}

Columbus, OH 43210-1106

40. Exploitation of Room Temperature Molecule/ Polymer Magnets for Magnetic and Electromagnetic Interference Shielding and Electromagnetic Induction Applications

Arthur J. Epstein

Department of Physics

614/292-1133

Funding Profile

Date Started: July 15, 1996

Anticipated Duration: 3 Years

FY $96-\$ 322,000$

FY $97-\$ 212,000$

FY $98-\$ 215,000$

There are increasing needs in today's society for lightweight, electromagnetic radiation shielding materials for operation at low frequencies ( $<\mathrm{Mhz}$ range). This is partially driven by the growth of electric power distribution, telecommunications, and electromechanical power devices; concerns about electromagnetic interference; and an increasing need for lightweight inductive materials for efficient and portable motors and transformers. We reported the first polymer(tetracyanoethylene)based magnet that remained strongly magnetic up to $350 \mathrm{~K}(170 \mathrm{~F})$. We also demonstrated that more-than doubling of the room temperature magnetization can be achieved using a new route. Molecule/polymer-based magnetic materials are technologically attractive due to anticipated room temperature synthesis, processing, and device manufacture. Though these materials are relatively new, we already demonstrated that unoptimized versions of the materials shield magnetic fields independent of frequency between 10 and 10 (4) $\mathrm{Hz}$ - a range difficult to shield using electrical conductors alone - with initial roomtemperature real permeabilities, $\mu(i)$, of 13 , which 
is close to iron. In late 1994 , a preliminary report from a French group disclosed that a second class of molecule-based magnets (based on mixedmetal Prussian Blue type materials) has magnetic transitions near room temperature. The report suggests that additional molecule-based magnetic materials may be suitable for magnetic shielding. We have now synthesized similar (but not identical) Prussian Blue type materials with vanadium replacing iron. Our preliminary results on these modified Prussian Blue type materials revealed an even higher saturation magnetization, though a lower transition temperature than reported by the French group, indicating opportunity for chemical tuning of the magnetic properties including initial permeabilities and transition temperatures. This project involves an integrated synthesis/ processing/characterization/modeling component to ascertain the feasibility of using molecule-based magnetic materials with emphasis on the study of the high Tc Prussian Blue-type magnetic materials from dc/low frequency to communications frequencies for shielding and induction applications. The objective of the project is to establish the ultimately achievable intrinsic real and imaginary magnetic permeabilities and corresponding electric permittivities and their control through synthesis and processing.

\section{Old Dominion University \\ Norfolk, VA 23529-0246}

41. Micro-Hollow Cathode Discharge Arrays: High Pressure, Nonthermal Plasma Sources

Karl H. Schoenbach

Physical Electronics Research Institute

757/683-4625

\section{Funding Profile}

Date Started: July 15, 1996

Anticipated Duration: 3 Years

FY 96 - $\$ 229,000$

FY $97-\$ 259,000$

FY $98-\$ 210,000$

Hollow cathode discharges are known as nonthermal plasma sources: the electron energy distribution in the two stages of the discharge (Predischarge and main discharge) contains a large percentage of high energy $(>10 \mathrm{eV})$ electrons. By reducing the size of the cathode holes from $\mathrm{cm}$ to ten's of $\mu \mathrm{m}$ we were able to extend their range of operation from subtorr range to almost atmospheric pressure. The presence of high-energy electrons and the measured characteristics of micro-hollow cathode discharges, such as: 1) positive current voltage characteristics, which allow the construction of discharge arrays without ballast, 2) stable operation for dc, ac, and pulsed voltages, 3 ) low applied voltage (several hundred volts), and 4) strong radiative emission in the UV, allow the utilization of micro-hollow cathode discharge arrays (MHCDAs) for flat panel displays, surface processing, gaseous emission treatment, and as broad area electron and ion sources. The MHCDAs consist either of sets of metal meshes, spaced a distance on the order of the hole diameter apart, or of metal-plated, perforated dielectric foils. The simplicity, low cost, and the low required voltage for hollow electrode arrays makes MHCDAs strong competitors to other electro-technologies which rely on nonthermal plasmas (such as barrier discharges, and pulsed corona discharges). This project will study the physics of micro-hollow cathode discharge operation in a positive differential conductivity mode. Particularly, the conditions for discharge array operation at atmospheric pressure will be explored, concentrating on the electron energy distribution and the spectral emission of microhollow cathode discharges. This project will focus on two applications: 1) UV light sources (excimer lamps) for food and water sterilization and for surface treatment; and (2) gas reactors for treatment of hazardous gases, such as perfluoro compounds, used in the semiconductor industry, and volatile organic compounds (VOC's).

\section{Princeton University \\ Princeton, NJ 08544-1009}

42. Molecular Surface Modification as a Means of Corrosion Control

Andrew B. Bocarsly

Department of Chemistry

609/258-3888

Funding Profile

Date Started: June 15, 1996

Anticipated Duration: 3 Years

FY $96-\$ 388,000$

FY 97 - $\$ 292,000$

FY $98-\$ 309,000$

Corrosion is a major materials problem in many industries. In the petrochemical industry which provides a major market for iron based materials, corrosion challenges exist from the production of 
hydrocarbons to their refining and conversion to chemical products. Corrosion of concern to the petrochemical industry occurs in a variety of environments ranging from highly acidic to alkaline, and temperatures ranging from room temperature up to $\sim 1100{ }^{\circ} \mathrm{C}$. The goal of this research is to investigate the chemistry of novel organic films (corrosion inhibitors) of $5 \AA$ to $20 \AA$ dimension that may provide a corrosion resistant barrier on the surface of metallic materials. Joint studies at Princeton University and Exxon Research and Engineering Company suggest that developments in the fields of surface science and materials chemistry are now at a point where an utilitarian molecular view of corrosion processes is possible. This capability is expected to allow for the "molecular design" of next generation inhibitors having the requisite properties to provide for corrosion protection under extreme chemical and thermal conditions. In the proposed research, which is a collaborative effort involving members of the Princeton Materials Institute and scientists from Exxon's Research and Engineering Laboratory, state-of-the-art surface characterization tools will be brought together to generate a molecular level understanding of model organic films appropriate for corrosion control. The mechanisms of film protection and film breakdown will be investigated thoroughly. The order and packing density of the films will be studied as a function of temperature, using Grazing Incidence X-ray Diffraction involving synchrotron $X$-radiation as a main characterization tool. The interface stability of the molecule, its bonding mechanism and dissociation pathways will be studied by using a combination of spectroscopies such as Temperature Programmed Desorption, High Resolution Electron Energy Loss Spectroscopy and Auger Electron Spectroscopy on model substrate surfaces. Additionally, low energy electron diffraction will be used to characterize the material surface after molecular debonding. The mechanistic understanding derived from these different techniques will be used to construct molecular frameworks that may provide corrosion resistance. The performance of these molecular architectures in real environments will be investigated using electrochemical reactors available at Exxon's Corporate Research Laboratories.
Princeton University

Princeton, NJ 08544-1009

43. Optimally Controlled Interior Manipulation of
Solids

Herschel Rabitz

Department of Chemistry

609/258-3917

Funding Profile

Date Started: November 19, 1992

Anticipated Duration: 4 Years*

FY $93-\$ 329,000$

FY $94-\$ 349,000$

FY $95-\$ 299,000$

In the processing of solid state materials, manipulation or modification is usually confined to their accessible exterior surfaces. This project is concerned with the development of a technique for modification of the interior solids without the necessity of opening up the material. The technique is based on the concept of designing and creating temporally and spatially tailored laser pulses that deposit energy on the surface for the purpose of launching an intense acoustic wave that focuses within the solid. Taking account of the relatively large illumination area on the surface and the focusing nature of the acoustic waves, it should be possible to minimally disrupt the surface while still attaining significant degrees of interior modification at the target volume. A central feature of this new materials processing method is its reliance on destructive and constructive interference between the ensuing shear and compressional acoustic waves. The delicacy of this method calls for the use of optimal design and control techniques for the temporal and spatial shaping of the laser beams. The research will consist of a theoretical design effort that closely interacts with a laboratory program for implementation of the design concepts. The research will be conducted in a series of steps, starting with low intensity focusing and proceeding to the regime where permanent solid interior alteration is possible. In accord with this sequential development, theoretical design work will move from the linear to the nonlinear regimes of solid mechanics and the laboratory studies will involve increasing laser pulse intensities and complexities of pulse shapes. The overall purpose of the research is to establish the feasibility of achieving interior manipulation of solids. Particular attention will be paid to discerning the flexibility as well as 
limitations of the physical process. An established capability for interior manipulation of solids would open up many opportunities including interior annealing, induced phase transitions, induced chemical reactions, crack arresting, controlled d effect site generation, and interior welding.

*Includes 12 month no-cost extension

\section{Sandia National Laboratories Albuquerque, NM 87185-0346}

\section{Semiconductor Broadband Light Emitters}

Paul Gourley

505/844-5806

Funding Profile

Date Started: December 1, 1994

Anticipated Duration: 3 Years

FY $95-\$ 330,000$

FY $96-\$ 382,000$

FY $97-\$ 390,000$

Semiconductors are compact, lightweight, operate in air, and are rugged. However, conventional semiconductor diodes emit light only into a narrow range of wavelengths. To obtain broadband emission, new structures are needed that utilize a wide range of alloy compositions available from modern semiconductor growth techniques. Fractal lattice and chirped quantum wells form a new class of materials which can provide broadband light emitters. The goal of this proposal is to develop such multi-alloy structures grown by metal organic vapor phase epitaxy and molecular beam epitaxy for efficient, broadband light emission. To develop broadband emitters, we will focus our efforts on this class of fractal and chirped quantum-wells structures utilizing InAIGaP alloys grown by metalorganic vapor phase epitaxy on GaAs substrates. The work will concentrate on three areas: materials design and growth, characterization and modelling, and device design and fabrication. The interplay of these three parallel efforts will lead to optimized device structures that emit broadband light with at least $300 \mathrm{meV}$ bandwidth in the green to red regions and a few percent external quantum efficiency. Materials and design parameters will be understood through a wide variety of experimental and theoretical tools. To implement this new class of broadband emitters, we will design, grow and fabricate light-emitting diode structures, and measure electroluminescence spectra, currentvoltage, and light-current characteristics.
Sandia National Laboratories Albuquerque, NM 87185-0346

45. Rapid Melt and Resolidification of Surface Layers Using Intense, Pulsed Ion Beams

Bob Turman

505/845-7119

Funding Profile

Date Started: November 1, 1994

Anticipated Duration: 3 Years

FY $95-\$ 300,000$

FY $96-\$ 300,000$

FY $97-\$ 300,000$

In the past, the introduction of new material surface treatments like galvanizing, sputtering, and plasma spraying have enabled new products and opened new markets. The capability to rapidly melt and resolidify surface layers using intense, pulsed ion beams can enable another such advance. This project will develop a next generation surface processing technology based on new, repetitively pulsed ion beams. Rapid solidification is known to greatly improve metal surface properties such as corrosion, wear, and fatigue resistance, but the lack of an economic and effective way to apply this technique to surfaces has prevented its use except in high value applications. Intense, pulsed, high energy ion beams treat surfaces based on surface melting followed by rapid thermal quenching by thermal diffusion into the underlying, untreated bulk material. This process produces non-equilibrium microstructures, nanocrystalline phases, and extended solid solutions leading to improved corrosion and friction properties of metals, as well as surface smoothing and defect healing, grain refinement, and modification of surface layer hardness. The low cost and in-depth deposition of high energy pulsed ion beams gives pulsed ion beam technology important advantages over laser treatment. The project will determine the capabilities and limitations of rapid melt and resolidification using pulsed ion beams. It will document the non-equilibrium micro-structures produced in treated layers and their effect on metal surface properties and will do the initial process development needed to show how this technique can be applied to commonly used metals. If successful, this will enable new ways to modify surfaces for enhanced properties and lifetimes with greatly improved energy efficiency and costeffectiveness and will enable a significant reduction in the use of heavy metal and solvent-based surface treatment coating processes. 
University of South Florida

4202 E. Fowler Avenue

Tampa, FL 33620-5700

46. Experimental and Theoretical investigation of Dual-Laser Ablation for Stoiachiometric LargeArea Multicomponent Film Growth

Sarath Witanachchi

Department of Physics

813/974-2789

Funding Profile

Date Started: August 15, 1996

Anticipated Duration: 3 Years

FY $96-\$ 147,000$

FY $97-\$ 108,000$

FY $98-\$ 113,000$

We have recently discovered a novel dual-laser ablation process that dramatically alters the dynamics of the conventional single-laser ablation process. Initial experiments, using this process, allowed the production of high quality defect-free films of $\mathrm{Y}(2) \mathrm{O}(3)$ that was not possible with single excimer laser ablation. This provides the motivation for our proposed research to investigate the physical mechanisms operative in this novel process. Two major problems associated with single laser ablation have hindered the development of this method as a manufacturing process. They are: 1) deposition of micron and submicron particulates; and 2) relatively narrow expansion profiles that limit the area of uniform film growth. Dual-laser ablation can potentially overcome both these major drawbacks while retaining the main advantages of the single laser ablation technique. We propose a systematic study to ascertain expansion characteristics of individual elements, with different volatility, in a multicomponent material system, under the dual-laser ablation process that would determine the required conditions for large-area defect-free stoichiometric film growth. A species-sensitive hydrodynamic model is proposed. This will provide a clear understanding of the basic mechanisms operative in this process, and thus aid the process optimization for any material system. The duallaser ablation system comprises a tandem combination of excimer and $\mathrm{CO}(2)$ laser pulses with an adjustable inter-pulse delay, that is spatially overlapped on the target. The primary objective of the research is to study experimentally the effect of the process parameters on the species velocity distribution and expansion profile for individual components, and to develop a species-sensitive theoretical model that is consistent with the experimental observations. The project will investigate a $\mathrm{Cu}$ target to establish the process characteristics for a single-element plume. It will also study the expansion characteristics of CulnSe(2) and $\mathrm{Cu}(\ln (1-x) \mathrm{Ga}(\mathrm{x})) \mathrm{Se}(2)$ plumes to explore the behavior of individual elements in multicomponent plumes. Investigation of spatial stoichiometric control of $\mathrm{Ga}$ in the $\mathrm{Cu}(\ln (1-\mathrm{x}) \mathrm{Ga}(\mathrm{x}$ )) $\mathrm{Se}(2)$ will aid semiconductor doping studies. The new understanding of the dual-laser ablation process will facilitate the extension of this method to other material systems. The method offers ease of control, simplicity and high-quality film growth, that could yield a method of choice for both epitaxial and highly oriented polycrystalline multicomponent film growth.

\section{TecOne}

1803 Sageway Drive

Tallahassee, FL 32303

\section{7. 'Off-Diagonal' Thermoelectricity for Cooling and Power Generation}

Louis R. Testardi

904/562-9789

\section{Funding Profile}

Date Started: June 1, 1995

Anticipated Duration: 3 Years

FY 95 - $\$ 170,000$

FY $96-\$ 166,000$

FY $97-\$ 170,000$

'Off-Diagonal' thermoelectricity, an uncommon effect which only occurs in low symmetry materials, allows unique and untried opportunities for thermal cooling, heat pumping and power generation. It utilizes the orthogonal coupling of heat and electric current flows in anisotropic media and opens new device as well as material development routes for the improvement of thermoelectric energy conversion. The advantages lie in a geometry naturally adapted to compact cooling, heat pumping and power generation with planar thermal boundaries, and also in electric impedances which allow a more compact, efficient and convenient device. The overall program goal is the development of a lightweight, flexible sheet material which will provide cooling, heat pumping and, with less application, power generation for objects or temperature baths of irregular geometry using 'off-diagonal' thermoelectricity. The principal materials thrust will be in conducting polymers 
because of their potential low cost and their ease of large scale processing to develop anisotropic properties. Applications include cooling of small volume consumerindustrial items, cooling and temperature control of the human body for medical treatment and comfort, and the utilization of waste heat from large area temperature baths.

\section{Texas A\&M University \\ College Station, TX 77843}

48. Utilizing Laser Spectroscopy of Noble Gas Tracers for Mapping Oil and Gas Deposits

Hans A. Schuessler

Physics Department

409/845-5455

Funding Profile

Date Started: December 15, 1992

Anticipated Duration: 4 Years*

FY $93-\$ 152,000$

FY $94-\$ 164,000$

FY 95 - $\$ 168,000$

Radioactive noble gases are being used as tracers to measure the structure of gas and oil deposits. Due to their chemical inertness, they offer the advantage that they do not react with the environment with which they are in contact. Usually, a noble gas tracer is injected at an injection well and gas or liquid samples are taken from a production well. When a long-lived tracer, such as (35) $\mathrm{Kr}$ (half-life $=10.8 \mathrm{y}$ ), is used for extended deposits, the specific activities of the production well samples are low. The measurements are then difficult, since the sample must be analyzed in an ultralow counting facility to minimize the background counts. This problem exists even when large amounts of tracer gas with high radioactivity levels (several hundred curie) are injected for which extensive safeguarding of the personnel is necessary. The objective of this project is to improve the sensitivity of noble gas detection in samples taken from production wells by more than three orders of magnitude by applying optical rather than nuclear detection. The novel technique will not only reduce the required radioactivity levels at the injection site, but work even with stable tracer isotopes thus abolishing most handling, transportation and storage problems. Collinear fast beam laser spectroscopy will be used for which a sensitivity at the few atoms level and also complete isotopic selectivity has already been demonstrated. The construction of a prototype analytical instrument is planned, that can routinely and quickly analyze samples for their noble gas content. Single noble gas atoms can then be detected, even in the presence of other isotopes and atoms which are more abundant by a factor of about 10(15). Since sample enrichment might not be necessary and stable noble gas tracers are inexpensive, the method promises to be more cost effective and environmentally safe than present nuclear decay detection.

*Includes 12 months no-cost extension

\section{University of Texas \\ Odessa, TX 79762-8301}

49. A Mild, Chemical Conversion of Cellulose to Hexane and Other Hydrocarbon Fuels.

\section{J. Michael Robinson \\ Chemistry Department \\ 915/552-2237}

\section{Funding Profile}

Date Started: January 15, 1995

Anticipated Duration: 3 Years

FY $95-\$ 350,000$

FY $96-\$ 300,000$

FY $97-\$ 260,000$

This project will develop a mild chemical reduction process that converts biomass with $100 \%$ carbon conversion into a hydrocarbon fuel. There are five requirements for such a conversion. 1) The carbon chain remains intact. 2) Each reaction occurs at mild conditions and gives a high yield. 3) Each reaction is catalytic and only hydrogen or electricity is consumed. 4) Initial reactions occur in an aqueous medium, which 5) allows the use of wet feedstocks. These requirements will be addressed beginning with the continued exploration of unique chemical reductions of components derived from biomass. Catalytic recycling of the chemical reducing agents provides the equivalent of an efficient biomass reduction. The objective of this project is to develop an efficient multistep chemical process for the conversion of the principal components of biomass, cellulose and hemicellulose, into hydrocarbon fuels. Separation of biomass into individual components allows use of selective reactions that give $100 \%$ carbon conversion. With a multistep reaction design, a single pure product such as hexane may result instead of a crude fuel mixture which results from pyrolysis methods. 


\section{University of Washington}

Seattle, WA 98195

50. Cryogenic Energy Storage System for Automotive Propulsion

Abraham Hertzberg

Aerospace and Energetics Research Program 206/543-6321

\section{Funding Profile}

Date Started: June 1, 1995

Anticipated Duration: 2 Years

FY $95-\$ 175,000$

FY $96-\$ 186,000$

Studies at the University of Washington indicate that liquid nitrogen is an effective energy storage medium which, when used for automotive purposes, offers significant advantages over current and proposed battery systems, both in performance and economy. Reasonably-sized liquid nitrogen propulsive systems can provide automotive ranges between 200 and 300 miles, with operating costs well below those of any other electric vehicle concepts. The range and performance can readily be extended with the addition of a small, low temperature combustor when operating as an ultra low emission vehicle. Some of the particular advantages are that refueling the cryogen only requires minutes and there are not environmental hazards in introducing a liquid nitrogen energy storage infrastructure. A two year research program designed to explore the advantages of a liquid nitrogen energy storage system for automotive propulsion will be carried out. In the first year the work will concentrate primarily on the heat exchanger element. During the second year a prototype heat exchanger system will be fabricated and tested under simulated road conditions.

\section{University of Washington \\ Seattle, WA 98195}

51. The Supersonic-Mixing, Shock-Wave Reactor: An Innovative Approach for Efficient Chemical Production

Arthur T. Mattick

Aerospace and Energetics Research Program 206/543-6181
Funding Profile

Date Started: June 15, 1993

Anticipated Duration: 4 Years*

FY $93-\$ 272,000$

FY $94-\$ 418,000$

FY $95-\$ 309,000$

The production of many commercially-important chemicals involves pyrolysis of hydrocarbon feedstocks, an energy-intensive process that is now carried out by heating components of oil or natural gas in a furnace. This research will examine the potential of a novel approach for pyrolysis, the supersonic-mixing, shock-wave reactor, for reducing the energy consumption and production cost of ethylene and other compounds. These benefits arise from the use of gasdynamic processes to precisely control the temperature history of a reactant and thereby maximize the yields of valuable products. Initial studies indicate that ethylene yields in the pyrolysis of ethane may be $20-40 \%$ higher by using this method in place of conventional technology, and energy consumption may be reduced by $15 \%$ or more. The research program entails: 1) experimental investigation of fundamental aspects of supersonic mixing and reacting gas streams, such as mixing shear layers, shock structure and uniformity, and reaction pathways, that are important in the reactor's operation; 2) measurement of product yields under conditions of pyrolysis expected in commercial applications of the reactor; and 3) examination of methods of implementing the reactor for chemical manufacture.

*Includes 12 month no-cost extension

Washington State University* Pullman, WA 99164-2814

52. Tunable Femtosecond UV Light Source Using a Novel Frequency Upshift Technique

Henry C. Kapteyn

Department of Physics

$509 / 335-4671$

Funding Profile

Date Started: April 19, 1993

Anticipated Duration: 2.5 years**

(Project Completed)

FY $93-\$ 156,000$

FY $94-\$ 158,000$ 
The goal of this project is to implement a new approach for producing ultrashort light pulses at ultraviolet to extreme-ultraviolet wavelengths. An intense light pulse can be used to create a moving ionization front; light can be reflected from this front and experience a relativistic Doppler upshift. Two recently-developed technologies now make it possible to create tunable light pulses of unprecedented short duration using this technique. First, the recent development of small-scale terawatt femtosecond laser systems makes it possible to create an extremely abrupt moving ionization front, using the process of multiphoton ionization. Second, recently-developed techniques have resulted in the generation of single-opticalcycle duration pulses in the far-infrared. It is shown herein that it is possible to upshift such pulses to optical and shorter wavelengths while still retaining nearly single-cycle duration. This way, pulses of 1-5 femtoseconds duration in the UV to XUV region of the spectrum can be created.

*On July 15,1996 , this project was transferred to the University of Michigan as a result of Professor Kapteyn's relocation.

**The total three-year funding for this project is $\$ 445,000$.

\section{Western Washington University \\ Vehicle Research Institute \\ Bellingham, WA 98225-9086}

\section{A Thermo-Photovoltaic Generator for Use in a Lightweight Electric Car}

Michael R. Seal

Department of Technology Engineering

360/650-3045

Funding Profile

Date Started: August 1, 1994

Anticipated Duration: 3 Years

FY 94 - $\$ 145,991$

FY $95-\$ 444,871$

FY $96-\$ 299,851$

In an internal combustion engine, fuel is mixed with air and periodically exploded. Because the explosions are of very short duration, the fuel combustion is incomplete, leading to carbon monoxide and hydrocarbon exhaust emissions. More pollution results because the temperature at the peak of the explosion is very high leading to the creation of nitrous oxides. A quiet, lightweight, clean, electric power source will be built in which a fuel is continuously burned in a ceramic tube, the tube glows red hot, and photovoltaic cells receive the infrared from this emitter and convert it to electric power. In effect, "solar" cells are used with a small manmade "sun" created by burning natural gas. Because fuel is burned continuously without periodic explosions, the thermophotovoltaic unit is very clean, quiet, efficient, and lightweight. The first benchtop experiments have already shown that this generator is $\mathbf{5 0}$ times cleaner than an internal combustion engine. Such a thermophotovoltaic unit has only recently become feasible as a result of new gallium antimonide cells fabricated by the JX Crystals Company. These new cells are much more sensitive in the infrared range than traditional solar cells. These new infrared cells will be integrated with an efficient natural gas fired infrared source with sufficient power to charge onboard vehicle batteries. The thermophotovoltaic eight cylinder unit alone, will be able to maintain an automobile at a speed of 60 miles per hour on level ground. Additional power for hill climbing and performance will be provided by onboard batteries. 



\section{SMALL BUSINESS INNOVATION RESEARCH PROGRAM}

The Small Business Innovation Research (SBIR) program was created in 1982 by Public Law $97-219$ and reauthorized in 1992 until the year 2000 by Public Law 102-564. Program objectives are: to increase private sector commercialization of technology developed through Federal R\&D; to increase small business participation in Federal R\&D; and to improve the Federal Government's dissemination of information to womenowned-, and economically disadvantaged small business concerns.

Agencies with extramural R\&D budgets of over $\$ 100$ million are required to conduct an SBIR program using a set-aside of a stated percentage of that budget. The percentage increased from an initial $0.2 \%$ in 1983 to $1.25 \%$ in 1986 through 1992. Public Law 102-564 increased the set-aside further, starting with $1.5 \%$ in 1993 and reaching a maximum of $2.5 \%$ in 1997. The Department's SBIR budget for FY 1996 was about $\$ 62$ million.

In the Department of Energy, SBIR funds are used to support an annual competition for Phase I awards of up to $\$ 75,000$ for about 6 months to explore the feasibility of innovative concepts. Only Phase I winners are eligible to compete for Phase II which is the principal research or R\&D phase. The maximum funding for Phase II projects in FY 1996 is $\$ 750,000$ over a two-year period. Technical topics for DOE's annual SBIR Solicitation are compiled by program managers in the agency.

In Fiscal Year 1996, the Advanced Energy Projects Division (AEP) managed two Phase I SBIR projects, awarded under the topic, "Mechanical Miniaturization and Nanoscale Electronics for Energy Applications," in the 1996 SBIR Program Solicitation. AEP is also managing four Phase II SBIR projects selected from grant applications submitted to the topic, "Novel Materials for Sustainable Energy Development," in the 1995 DOE SBIR Program Solicitation, and six Phase II SBIR projects selected from the 1994 DOE SBIR Program Solicitation, of which three were under the topic, "Green Car: Scientific Approaches to Automotive Applications (subtopic - Novel Approaches to Propelling Automobiles)" and three were under the topic, "Design and Applications of Novel Materials." Five additional Phase II SBIR projects, selected from grant applications submitted to the topic, "Design and Applications of Novel Materials," in the 1993 DOE SBIR Program Solicitation, were managed by AEP. 



\section{PHASE I SBIR PROJECTS}

Angstrom Devices, Inc. 2849 East Elvira Road

Tucson, AZ 85706-7126

54. Passive Electronic Components From Nanostructured Materials

Thomas Venable

520/294-7115

Funding Profile

Date Started: August 13, 1996

FY $1996-\$ 75,000$

Passive electronic components play a critical role in ensuring efficient and reliable generation, delivery, and use of energy. Existing passive components were discovered a few decades ago and are all based on bulk material properties. Although miniaturization of these components have enabled dramatic performance improvements, it is increasingly envisioned that fundamental breakthroughs would be necessary to satisfy the future needs of our nation's energy infrastructure. Nanostructured materials - materials whose domain sizes have been confined to dimensions less than $100 \mathrm{~nm}$ - potentially offer such a breakthrough because of the unique combination of non-bulk like properties they exhibit. Angstrom Devices, Inc. (ADI) seeks to capitalize on this opportunity and investigate, develop, and commercialize passive electronic components from nanostructured materials. ADI's technical approach during Phase I will be to establish the proof-ofconcept by demonstrating passive components prepared from nanostructured materials. Phase II will optimize the proposed technology, develop prototype devices, and field test the devices with lead customers. Phase III will commercialize the technology.
Integrated Microtransducer Electronics Corp. 1214 Oxford Street

Berkeley, CA 94709-1423

\section{Thin-Film, Micron-Scale Transformers}

Richard Spitzer

510/841-585

Funding Profile

Date Started: August 13, 1996

FY $1996-\$ 74,742$

A basic problem with thin-film transformers is the high value of the low-frequency cutoff. The applicant has developed multilayer, thin magnetic films that offer the potential for eliminating this problem. The transformer is based on an active giant magnetoresistive (GMR) device that will work even down to DC. The input is completely isolated from the output; there is no resistive path between the two. Both voltage and current can be stepped either up or down. Because of its large bandwidth, the transformer is suitable for both analog and some digital circuitry. It can be fabricated on the same substrate as other GMR-based logic circuits and memory elements. The proposed Phase I effort will demonstrate the feasibility of using these films to develop useful micron-scale transformers through design, calculation, fabrication, and testing. 

Advanced Modular Power Systems, Inc. 4667 Freedom Drive

Ann Arbor, MI 48108

\author{
56. A Low Emission AMTEC Automotive Power \\ System
}

Thomas K. Hunt

313/677-4260

Funding Profile

Date Started: June 21, 1995

FY $95-\$ 331,248$

FY $96-\$ 418,609$

The alkali metal thermal to electric converter (AMTEC) is a static energy conversion device that operates at thermal to electric conversion efficiencies that are independent of size, have reached $19 \%$ efficiency, and are expected to reach $25 \%$ to $30 \%$ soon. These systems operate silently, with no moving parts and can utilize any source capable of delivering heat at 700 degrees $C$ to 900 degrees $C$. Because they are efficient and small internal combustion engines with a wide range of output (within $5 \%$ of peak efficiency from $15 \%$ to $85 \%$ of full power), but use external combustion, they are expected to have the lowest emissions possible for a given electrical output. Their output is DC and, with appropriate series connection of modules, AMTEC can deliver voltages to match those provided by the battery systems of electric vehicles either for charging or for direct operation of electric motor drives. While AMTEC systems have been under development for years, recent advances made in programs directed toward spacecraft power systems have led to much simpler cell designs, far higher reliability, greatly improved modeling methods, and a clear path to modules appropriate for the assembly of multikilowatt systems. Phase I demonstrated an $18 \%$ efficient single-tube cell and the feasibility of producing, operating, and accurately modeling the experimental performance of multi-tube, seriesconnected AMTEC cells. In Phase II, a full-scale system design will be developed and used to guide experiments that allow a clear test of the feasibility of the AMTEC approach. A series of experimental cells will demonstrate the advanced component technologies required to reach $35 \%$ to $40 \%$ thermal efficiency, and the analytical models will then be used to determine the feasibility of a full-scale system. Phase II will conclude with an assessment of AMTEC utility for vehicle applications.

\author{
Advanced Refractory Technologies, Inc. \\ 699 Hertel Avenue \\ Buffalo, NY 14207
}

57. Porous Aluminum Nitride Part Fabrication to
Support Advanced Battery Development

Thomas J. Mroz, Jr. 716/875-4091

Funding Profile

Date Started: April 1, 1994

FY $94-\$ 599,703$

In Phase I, sintered porous Aluminum Nitride (AIN) materials were shown to be suitable for separators in lithium-metal sulfide batteries. The sintered separator improves the structural integrity of the battery and allows reduction of the cell size. However, the current cost of AIN separators is more than the currently used Magnesium Oxide (MgO) powder materials. Methods of decreasing the cost of AIN separators have been identified they involve reduction in powder cost, improvements in tape processing methods, and utilization of continuous firing methods. This project will investigate methods of obtaining these cost reductions through processing improvements. Additionally, extended battery testing will be performed to assist in separator plate optimization and to develop baseline characteristics for baseline development. Opportunities within the process have been identified that will provide suitable cost savings which would result in a cost competitive separator concept. Battery fabricators identified in Phase I will be used to evaluate these AIN separators in preparation for commercialization of the concept in Phase III. Other non-battery opportunities for the porous AIN structure have been identified which provide additional avenues for product commercialization. 
American Superconductor Corporation

2 Technology Drive

Westborough, MA 01581

58. Oxide Dispersion Strengthened Silver for Use in High-Temperature Superconductor Composite Wires

Gilbert N. Riley, Jr. 508/836-4200

Funding Profile

Date Started: July 18, 1994

FY $94-\$ 125,000$

FY $95-\$ 475,000$

The strengthening of high-temperature superconductor (HTS) composite conductors with oxygen dispersion strengthened (ODS) silver is planned. State-of-the-art HTS composite conductors consist of ceramic superconductor filaments encased in a silver $(\mathrm{Ag})$ sheath. For reasons of chemical compatibility and oxygen permeability, silver is the only material that can be used to sheathe HTS. However, the current method of manufacture weakens the silver sheath, resulting in reduced HTS conductor strengths. The low strength of these composite conductors is a major obstacle in the development of HTS wires for applications requiring robust conductors such as power transmission cables, SMES, and motors. ODS increases the strength of the sheath, while maintaining chemical compatibility and oxygen permeability of silver. In Phase 1, two ODS-Ag systems and a method of fabrication were identified that provide the necessary thermomechanical stability and strength. Specific process issues unique to the materials and methods identified in Phase I will be addressed. Using insights gained from process-property-microstructure relationships and statistically designed experimental techniques, novel processes that simultaneously optimize the performance of the ODS-Ag sheath and the HTS will be developed. The resulting technology will be scaled up so that long lengths (approx. $1 \mathrm{~km}$ ) of high strength and high-performance HTS composite conductor can be manufactured on a routine basis.
Aspen Systems, Inc.

184 Cedar Hill Street

Marlborough, MA 01752-3017

59. Low Cost, Contamination-Tolerant
Electrocatalysts for Low-Temperature Fuel
Cells

Jaeseok Ryu

508/481-5058

Funding Profile

Date Started: July 9, 1996

FY $96-\$ 343,750$

FY $97-\$ 406,250$

Power generation from fuel cells via reformed gaseous fuel or direct methanol oxidation is a very attractive option for fuel cell vehicles or other mobile systems. One of the major road blocks to large-scale consumer applications of the fuel cell technology is the high cost and limited supply of the noble metal-based catalysts and catalyst poisoning. Group VI metal carbides, such as molybdenum carbides, tungsten carbides, or their mixtures, exhibited high catalytic activity toward electro-oxidation of the methanol. In addition, these catalysts are tolerant of $\mathrm{CO}$ contamination in the reaction zone. In order to develop low cost, contamination-tolerant electrocatalysts, Aspen Systems proposes an innovative chemical reduction process. In Phase I, we successfully produced nanosize metal carbides via a chemical reduction process. Measured crystallite size of metal carbides was as small as $2.5 \mathrm{~nm}$. We also demonstrated relatively good electrocatalytic activity of the metal carbides for hydrogen oxidation, oxygen reduction and direct methanol oxidation. In addition, we experimentally demonstrated the CO-tolerant nature of metal carbides. Electrochemical performance of these catalysts were not affected by $100 \mathrm{ppm} \mathrm{CO}$ concentration in hydrogen. In Phase II, we will optimize the chemical reduction process and post-heat treatment conditions to further improve electrochemical activity of these materials. We will also optimize the electrode structure/configuration to fully utilize the fine particle size of these catalysts. In addition, we will fabricate membrane electrode assemblies; utilizing metal carbide catalysts. Finally, we will demonstrate the contaminant-tolerance of the single cell with metal carbide catalysts by operating it on CO-containing hydrogen (up to several $\% \mathrm{CO}$ ). 
Chemat Technology, Inc.

19365 Business Center Drive

Suite 8

Northridge, CA 91324

60. Capacitive Energy Storage Using High Surface Area Hafnium Compounds

Haixing Zheng

$818 / 727 / 9786$

Funding Profile

Date Started: July 18, 1994

FY $94-\$ 125,000$

FY $95-\$ 475,000$

High surface area materials have diverse applications, such as for energy storage systems and for catalytic converters. In Phase I, the feasibility of fabricating transition metal compounds with high surface area and high double layer capacitance, using the sol-gel process, has been demonstrated, and a supercapacitor cell has been prepared in the Phase I research. Several approaches have been tried to prepare these carbides, nitrides, and borides of high surface area with the focus on hafnium compounds which have the highest capacitance of $>200$ microfarad $/ \mathrm{cm}(2)$. Hafnium carbonitrides with surface area up to 123 $\mathrm{m}(2) / \mathrm{g}$ have been fabricated and the supercapacitor cell has been constructed using these porous hafnium carbonitrides. The cell has an energy density of $6.4 \mathrm{~J} / \mathrm{g}$, which is close to the $10 \mathrm{~J} / \mathrm{g}$ energy density of ruthenium dioxide [RuO(2)]. In Phase II, energy storage capabilities will be enhanced by increasing the surface area of hafnium carbonitride and tailoring the chemistry of the pore surface. The best processing variables for fabricating the capacitive energy storage cells will be identified. The optimized cells will be tested for various properties: operation temperature, working voltage, capacitance, equivalence series resistance, and leakage current. All technical parameters will be measured and a technical database on these supercapacitors will be prepared for future commercialization of the supercapacitors. The process will be scaled up to pilot plant stage, and the production cost will be estimated.
EIC Laboratories, Inc.

111 Downey Street

Norwood, MA 02062

\section{Economical Photochromic Films Based On Metal Oxides}

R. David Rauh

617/769-9430

Funding Profile

Date Started: June 21, 1995

FY $95-\$ 249,250$

FY $96-\$ 487,470$

The goal of this work is to develop a robust thin film coating, less than two microns thick, that can be applied to surfaces, rendering them photochromic in sunlight with respect to both the visible and near infrared components of the solar spectrum. Computer models have anticipated that photochromic windows would give rise to significant energy savings by solar management, particularly in buildings dominated by their cooling load. The proposed coatings are derived from thin film transition metal oxides and are expected to be economical in materials and preparation, robust, and insensitive to environmental degradation. The objective of Phase I was to demonstrate a new highly active metal oxide film employing a novel means of sensitization. The photocoloration rate of tungsten oxide was increased 16-fold using this approach and the final optical density by a factor of three. The best Phase I films showed photocoloration under simulated solar conditions from 0.8 to 0.3 luminous transmittance with a coloration time of about 30 minutes, sufficient for energy control applications. However, bleaching times in air exceeded 24 hours and the dynamic range degraded after a few cycles. The objective of Phase II is to further improve the technology to achieve films with similar dynamic coloration properties but with bleaching rates in the dark of about 30 minutes and greater than one thousand cycles without loss of dynamic range. The Phase II research and development will focus on the reversibility of the sensitization process along with film fabrication methods applicable to the incorporation of a variety of possible sensitizer materials, extending approaches initiated in Phase I. Phase II will also develop a process for deposition onto polymer substrates used in window control films. Analyses of manufacturing costs and of solar energy transfer through windows incorporating photochromic films will also be 
carried out, permitting a final estimate of energy payback in various climates.

Giner, Inc.

14 Spring Street

Waltham, MA 02154-4497

62. An Integrated Catalyst/Collector Structure for Regenerative Proton-Exchange Membrane Fuel Cells

Larry L. Swette

617/899-7270

Funding Profile

Date Started: July 9, 1996

FY $96-\$ 379,597$

FY $97-\$ 339,550$

Dedicated proton-exchange membrane (PEM) fuel cells, electrolyzers and single-unit regenerative fuel cells (RFCS) have been identified by DOE as simplified technology of potential benefit to the electric vehicle and energy storage programs. Bifunctional catalysts and electrode structures to support the alternating gas evoludon/consumption modes of PEMRFCs have been developed by Giner, Inc. for both negative and positive electrodes. Full implementation of this technology requires the development of a suitable gas-diffusion/current-collection interface ( $G \mathrm{Cl})$ structure for the positive electrode to yield superior performance, stability and simplicity in bifunctional operation. The $\mathrm{GCl}$ structure proposed for development is based on a stabilized, wetproofed porous metal sinter with embedded shapes on the gas side (channels or pin fields) to facilitate bulk fluid distribution, and a flat surface on the membrane side to which a thin catalytic layer can be laminated. In Phase I, the potential feasibility of several small size prototype approximations of this $\mathrm{GCl}$ structure were evaluated. Three types of porous metal sheet were successfully prepared (two with machined grooves), stabilized, wetproofed, catalyzed and tested in a small PEMRFC $\left(36 \mathrm{~cm}^{2}\right)$, with promising results. For Phase II we propose the development of integral embedded shapes in the porous metal sinter together with some variations in porosity and pore size. When suitable structures have been identified they will be scaled up (e.g., 5" $\times 5^{\prime \prime}, 160 \mathrm{~cm}^{2}$ ) and tested more extensively as both single cells and multi-cell stacks.
Harvest Technology

9253 Glen Oaks Boulevard

Sun Valley, CA 91352-2614

63. Molten Film High-Intensity Paper Drying

David Warren

818/767-3157

Funding Profile

Date Started: July 9, 1996

FY $96-\$ 326,834$

FY $97-\$ 363,059$

A novel, molten-fluid drying technology is being developed to substantially reduce the capital and operating costs for the manufacture of paper products such as writing papers, packaging papers, and paperboard. The technology involves contacting molten fluids of unique property against the wet paper web so as to impart heat for drying in a more energy efficient and cost effective manner compared to current evaporative dryers. Phase I tests using prewetted commercial kraft papers of $30 \#$ and $75 \#$ grade were conducted on an experimental molten fluid dryer which showed that average drying rates of $40 \mathrm{lb} / \mathrm{ft}(2) / \mathrm{hr}$, or an order of magnitude higher than current cylinder drying technology, were achievable without the use of ventilation air. Engineering studies indicate that the dryer can reduce equipment size by $60 \%-75 \%$ and capital costs by greater than $50 \%$. Because no ventilation air is required, the dryer energy efficiency is increased by $20 \%$ and the recoverable waste heat dramatically increases from $10 \%$ to $90 \%$. SEM/EDX analyses showed that no molten material adheres to the paper surface during drying, and product property measurements showed the dried paper samples to be of high quality. The Phase II program will involve construction and testing of a molten fluid drying system with a drying capacity of $1000 \mathrm{lb} / \mathrm{hr}$ of sheet moisture. After initial development and testing, the dryer will be integrated with a Black Clawson pilot-scale paper machine to assess the performance of this technology under conditions that closely simulate the commercial production environment. These tests will provide the basis for Phase III field demonstration tests at an operating mill. 
ISM Technologies, Inc.

9965 Carroll Canyon Road

San Diego, CA 92131

64. Low Temperature Deposition of Titanium
Nitride

Anthony J. Perry

619/530-2332

Funding Profile

Date Started: July 18, 1994

FY $94-\$ 124,933$

FY $95-\$ 474,744$

Titanium Nitride (TiN) has been found to be an excellent coating for wear resistant applications. However, the deposition temperature of about 450 degrees $\mathrm{C}$ is far too high for many applications for machine component parts made from alloy steels or aluminum alloys, where deposition temperatures over 150 degrees $\mathrm{C}$ would deleteriously affect the mechanical properties of the substrates. When TiN coatings deposited at such a temperature, using current conventional industrial technologies, the micro-structure is not dense and the resulting coatings have mechanical properties far inferior to those made at the higher temperatures. Phase I demonstrated that hard, well-adhering TiN with low residual stress and a dense micro-structure can indeed be made at 150 degrees $C$ (by reactive deposition from a cathodic arc evaporation source) using the Hyper-lon process developed by ISM Technologies. In the Hyper-lon process, a pulsed high voltage bias is applied to the work-piece which produces this marked improvement in properties. In Phase II, the deposition process should be further developed and refined to produce a welldefined coating process, which can be scaled up into production, aimed at providing optimized wear resistance industrial parts.

JX Crystals Inc.

1105 12th Avenue, NW

Suite A-2

Issaquah, WA 98027-8994

65. A Clean and Efficient Thermophotovoltaic Generator for Electric Vehicles

Lewis M. Fraas

206/392-5237

Funding Profile

Date Started: June 21, 1995
FY 95 - $\$ 253,675$

FY $96-\$ 496,322$

This project is developing thermophotovoltaic energy systems to address several problems with conventional small electric generators. Conventional internal combustion models are widely used in the commercial and military sectors for remote, back-up, and portable power. Existing problems include low fuel efficiency, high maintenance, emissions, and noise. Using a thermophotovoltaic energy system to cogenerate electricity and heat, all of these problems can be addressed. In Phase I, a thermophotovoltaic demonstration unit was developed. This proved the concept of generating electricity by surrounding an emitter radiating in the infrared with infraredsensitive photovoltaic cells. With a fan as the only moving part, this clearly demonstrated low noise and the potential for low maintenance. By maintaining a constant burn temperature, emissions were much lower than those from a periodically exploding internal combustion engine. Finally, the potential for high efficiency by using the waste heat for space and water heating is evident, and achieving the cost and size of existing generators appears feasible. The planned effort for Phase II is the optimization of key components, development of a one kilowatt cogenerator, and the installation of a thermophotovoltaic system into an existing electric car. The Phase II effort provides valuable component optimization and another iteration of generator development for this electric vehicle effort, as well as taking the natural step of installing the multi-kilowatt generator in a car. More importantly, Phase II will provide a full-scale demonstration of the cogeneration technology.

\section{Nanomaterials Research Corporation \\ 2849 East Elvira Road \\ Tucson, AZ 85706-7126}

66. Nanostructured Insterstitial Alloys as Catalysts for Direct Energy Applications

Tapesh Yadav

520/294-7115

Funding Profile

Date Started: March 24, 1996

FY $96-\$ 361,826$

FY 97 - $\$ 388,174$

According to some estimates, U.S. manufactured products that depend on catalysis technologies 
account for over $\$ 500$ billion per year and include petroleum products, vehicle and industry emission controls, chemicals, pharmaceuticals, plastics and rubber, and food products. But frequently, precious metals such as platinum $(P t)$ and palladium $(P d)$ must be used as catalysts. They have the disadvantage of being expensive $(\$ 3,000$ to $\$ 15,000 / \mathrm{b}$ ) and must be imported in large quantities. A breakthrough in catalyst performance and catalytic materials could enhance $U$. S. competitiveness, reduce environmental impact, and improve energy efficiencies. During Phase I, a proof-of-concept of one such breakthrough was demonstrated. It was shown that nanostructured interstitial alloy-based catalysts: (a) show activity similar to Pt and Pd; (b) can be readily synthesized in desired form; and (c) show significant room temperature activity for a high volume, commercially important chemical reaction. Phase II will focus on scale-up and optimization of the nanostructured catalyst's synthesis and performance. Also, in collaboration with a leading catalyst manufacturer, bulk quantities of the catalysts will be field-tested. In order to identify and pursue spin-off commercialization opportunities, other commercially important chemical reactions that are presently catalyzed only by precious metals will be explored.

Selee Corporation

700 Shepard Street

Hendersonville, NC 28792

67. High Strength Ceria-Zirconia Toughened Alumina Ceramic with Superior High Temperature Strength and Corrosion Resistance

Giulio A. Rossi

704/697-2411

Funding Profile

Date Started: June 21, 1995

FY 95 - $\$ 145,398$

FY 96 - $\$ 279,767$

This project deals with the development of a novel ceramic material with superior strength and corrosion and erosion resistance in hightemperature environments. This material was shown to exhibit strength and thermal shock resistance superior to that of alumina and mullite. Phase I showed it to have excellent resistance to high temperature sulfates and alkalies, though the tests were not of long enough duration to demonstrate this conclusively. In Phase II, samples of open celled ceramic foam will be fabricated by impregnation of a polyurethane foam with an aqueous ceramic slurry followed by drying and firing to burn out organic material and densify the foam struts at high temperature. Several variables will be studied including zirconia/alumina ratio, particle size and several processing variables. The samples will be physically characterized. Hightemperature cycling will also be done using a gas burner rig. Degradation of modulus of elasticity as the result of thermal cycling will be carried out Samples will also be exposed to high temperature and pressure in atmospheres typical of the integrated gasification combined cycle and pressurized fluid bed combustor coal burning processes. The exposed samples will be examined for evidence of chemical attack.

Space Power, Inc.

621 River Oaks Parkway

San Jose, CA 95134

68. Design and Applications of Close-Spaced Thermionic Converters with Novel Isothermal Electrodes

Gary O. Fitzpatrick 408/434-9500

Funding Profile

Date Started: June 21, 1995

FY 95 - $\$ 253,676$

FY $96-\$ 496,324$

Thermionic converters with close-spaced interelectrode gaps are capable of substantial performance improvements over conventional ignited mode diodes. At very close gaps (two to 10 microns), a thermionic converter operates in the collisionless Knudsen mode with nearly double the output voltage of conventional diodes and concomitant increases of efficiency. In Phase I, a special electrode structure that can accommodate high heat flux without distortion was investigated. This type of electrode is needed in order to maintain an interelectrode gap of about five microns and to avoid short circuiting by thermal expansion deformation. In Phase I, a laser interferometric technique was also developed to measure the thermal expansion deformation of electrodes with high heat fluxes passing through them. In Phase II, the electrode investigation is further extended with new features to increase power density and higher operating temperatures. 
The higher power density operation is attractive for utility topping cycles and cogeneration. Additional experiments using laser interferometry will be carried out in Phase II and complete thermionic converters with novel features to produce substantially increased efficiency and power density will be tested. Prototypic devices with silicon carbide hot shells will be constructed and operated in an effort to develop a practical diode for commercial applications. Although electrical heat sources will be used for experimentation in Phase II, the type of converters that will be built would be suitable for operation with flame heat sources or solar concentrators operating in atmospheric air.

Thermal Electric Devices, Inc.

1704 Stanford Dr. NE

Albuquerque, NM 87106

69. Development of Metal Hydride Materials for High Coefficient of Performance Heat Pumps

K. Thomas Feldman, Jr. 505/268-0154

Funding Profile

Date Started: March 11, 1995

FY $95-\$ 375,000$

FY $96-\$ 375,000$

An efficient hydride reactor is necessary to allow an environmentally clean hydride heat pump to achieve its potential to be twice as efficient as current systems. A practical and cost effective method of coating hydride particles with high thermal conductivity copper and then compressing and sintering them into porous powder metal hydride (PMH) compacts with improved heat transfer was developed in Phase 1 . Thermal conductivity, $k=7.5 \mathrm{~W} /(\mathrm{m}$.degrees $\mathrm{C})$ was measured on green PMH compact pellets, a factor of 18 better than that of uncoated hydride particles. Transient analysis of reactor performance with a numerical code indicates only $\mathrm{k}=5 \mathrm{~W} /(\mathrm{m}$. degrees C) is required to achieve an adequate heat transfer rate for the heat pump. Further optimization of the PMH compacts is needed to improve thermal conductivity to $10 \mathrm{~W} /(\mathrm{m}$.degrees $\mathrm{C})$ which will provide excellent heat pump performance. Phase I results are highly promising. Phase II will further develop the PMH compacts into the shape of disks that can be press fit into a hydride reactor. The PMH compact disks will have grooves to improve hydrogen flow and will have thermal conductivity of at least $10 \mathrm{~W} /$ (m.degrees $\mathrm{C}$ ). PMH compact disks with embedded high thermal conductivity fibers will be explored as composite structures with high thermal conductivity and strength. Hydride reactors with these PMH compact disks will be built and tested for thermal performance. The numerical analysis code for heat-driven hydride reactors will be rewritten to describe the more promising compressor-driven hydride heat pump. The performance of the hydride heat pump, including electric energy consumption, cooling rate, coefficient of performance, weight, volume, cost, and life cycle cost, will be predicted and compared both with the experimental test data and with performance data of conventional vapor compression systems.

\section{Ultramet \\ 12173 Montague Street \\ Pacoima CA 91331}

70. Coated Micrograin Carbides for Wear Resistance

Andrew J. Sherman

818/899-0236

Funding Profile

Date Started: July 18, 1994

FY $94-\$ 124,908$

FY $95-\$ 474,649$

Micrograin carbides are small grain size (1-5 micron diameter) particles of tungsten carbide (WC) that have been "cemented" together with a predominantly cobalt matrix by liquid-phase sintering. The result is an excellent material for carbide cutting tools and other wear- and/or corrosion-resistant parts, because their finer grain size yields better mechanical properties than typical carbide tools (with grain sizes 20-50 micron). Some of their potential advantage is negated, however, by the difficulty of handling such fine powders and mixing them with cobalt powders to form the blend which is then preformed and sintered. Problems arising during handling and blending include increased impurity content, nonhomogeneous distribution of matrix powders, and WC-WC particle contact, all of which lower mechanical properties in the finished part. Also, substantial grain growth occurs during the liquidphase sintering step. The result is that cobalt content must be increased to achieve the desired fracture toughness and transverse rupture strength, with a corresponding decrease in tool hardness 
and life and an increase in tool cost. In Phase I, the feasibility of coating individual WC grains with the proper thickness of cobalt matrix was demonstrated. After consolidation, the problems of WC-WC particle contact and mixed carbide formation were found to be eliminated. Improved mechanical properties and performance over conventional micrograin carbides were obtained. The process permitted faster consolidation times and yielded lower impurity content with less deleterious interaction between matrix and carbide, as well as a large reduction in the amount of cobalt required. In Phase II, the process for coating WC/mixed carbide powders with cobalt will be optimized. A $40 \%$ increase in tool life (reduced wear rate) at constant mechanical properties and lower cobalt content, and/or a 50\% increase in tool toughness (and hence strength) at constant wear is expected. 
PROGRAM DATA

OFFICE OF COMPUTATIONAL AND TECHNOLOGY RESEARCH

ADVANCED ENERGY PROJECTS DIVISION

\section{BUDGET}

FY 1995

$\$ 11,085,000$

242,000
FY 1996

$\$ 11,652,000$

300,000
FY 1997

(REQUEST)

$\$ 11,492,000$ 300,000

\section{DISTRIBUTION OF FY 1996 FUNDS}

Universities

$44 \%$

DOE Laboratories

$50 \%$

Other

$6 \%$ 

INVESTIGATOR INDEX

(Project Numbers)

Anders, Simone

19

Antonio, Mark R.

Benson, David K.

Bhattacharya, Mrinal

Bionta, Richard M.

Bocarsly, Andrew B.

Bromberg, Leslie

Danna, Kathleen J.

Datta, Ravindra

Dowben, Peter A.

Epstein, Arthur J.

Farmer, Joseph C.

Fitzpatrick, Gary O.

Feldman, Jr., K. Thomas

Fraas, Lewis $M$.

Gantor, Miroslav F.

Gourley, Paul

Greenbaum, Elias

Gschneidner, Jr., Karl A.

Hanna, Mark C.

Heeger, Alan

Hertzberg, Abraham

Huffman, Donald R.

Hunt, Thomas K.

Jensen, Reed J.

Jiles, David C.

Johnson, Paul

Kapteyn, Henry C.

Kazmerski, Lawrence L.

Koppang, Richard R.

Mattick, Arthur T.

Michl, Josef

Migliori, Albert

Mroz, Jr., Thomas J.

Nastasi, Michael

Nozik, Arthur J.

Parkinson, Bruce

Perry, Anthony J.

Rabitz, Herschel

Radosz, M.

Rauh, R. David

Reiss, Howard

Riley, Jr., Gilbert N.

Robinson, J. Michael

Rose, M. Frank

Rosen, Moshe

Rossi, Giulio A.

Rubin, Michael D.

Ryu, Jaeseok

Schoenbach, Karl H.

Schuessler, Hans A.

Seal, Michael R.
Sherman, Andrew J. $\quad 70$

Skelly, David W. $\quad 16$

Spitzer, Richard $\quad 55$

Stangle, Gregory C. 1

Swette, Larry L. $\quad 62$

Testardi, Louis R. $\quad 47$

Tran, Tri D. 24

Turman, Bob 45

Venable, Thomas $\quad 54$

Warren, David 63

Was, Gary S. 32

Wiederrecht, Gary P. $\quad 6$

Witanachchi, Sarath . 46

Wong, Alfred $Y$. 9

Xiang, X. D. $\quad 21$

Yadav, Tapesh 6

Zheng, Haixing $\quad 60$ 
(Project Numbers)

Advanced Modular Power Systems, Inc.

Advanced Refractory Technologies, Inc.

Alfred University

American Superconductor Corporation

American University

Ames Laboratory

Angstrom Devices, Inc.

Argonne National Laboratory

Arizona, University of

5,6

Aspen Systems, Inc.

Auburn University

California, University of, Los Angeles

California, University of, Santa Barbara

Chemat Technology, Inc.

Colorado, University of

Colorado State University

EIC Laboratories, Inc.

Energy and Environmental Research Corporation

Florida International University

General Electric Company

Giner, Inc.

Harvest Technology

Integrated Microtransducer Electronics Corporation

lowa, University of

ISM Technologies, Inc.

Johns Hopkins University

JX Crystals, Inc.

Lawrence Berkeley Laboratory

Lawrence Livermore National Laboratory

Los Alamos National Laboratory

Louisiana State University

Massachusetts Institute of Technology

Michigan, University of

Minnesota, University of

Nanomaterials Research Corporation

National Renewable Energy Laboratory

Nebraska, University of

Oak Ridge National Laboratory

Ohio State University

Old Dominion University

Princeton University

Sandia National Laboratories, Albuquerque

Selee Corporation

South Florida, University of

Space Power, Inc.

TecOne

Texas A\&M University

Texas, University of

Thermal Electric Devices, Inc.

Ultramet

Washington, University of

Washington State University

Western Washington University 
DATE:

TO: Advanced Energy Projects Division

ER-33, GTN

U.S. Department of Energy

19901 Germantown Road

Germantown, MD 20874-1290

FROM:

(inc. tel \#)

SIGNATURE:

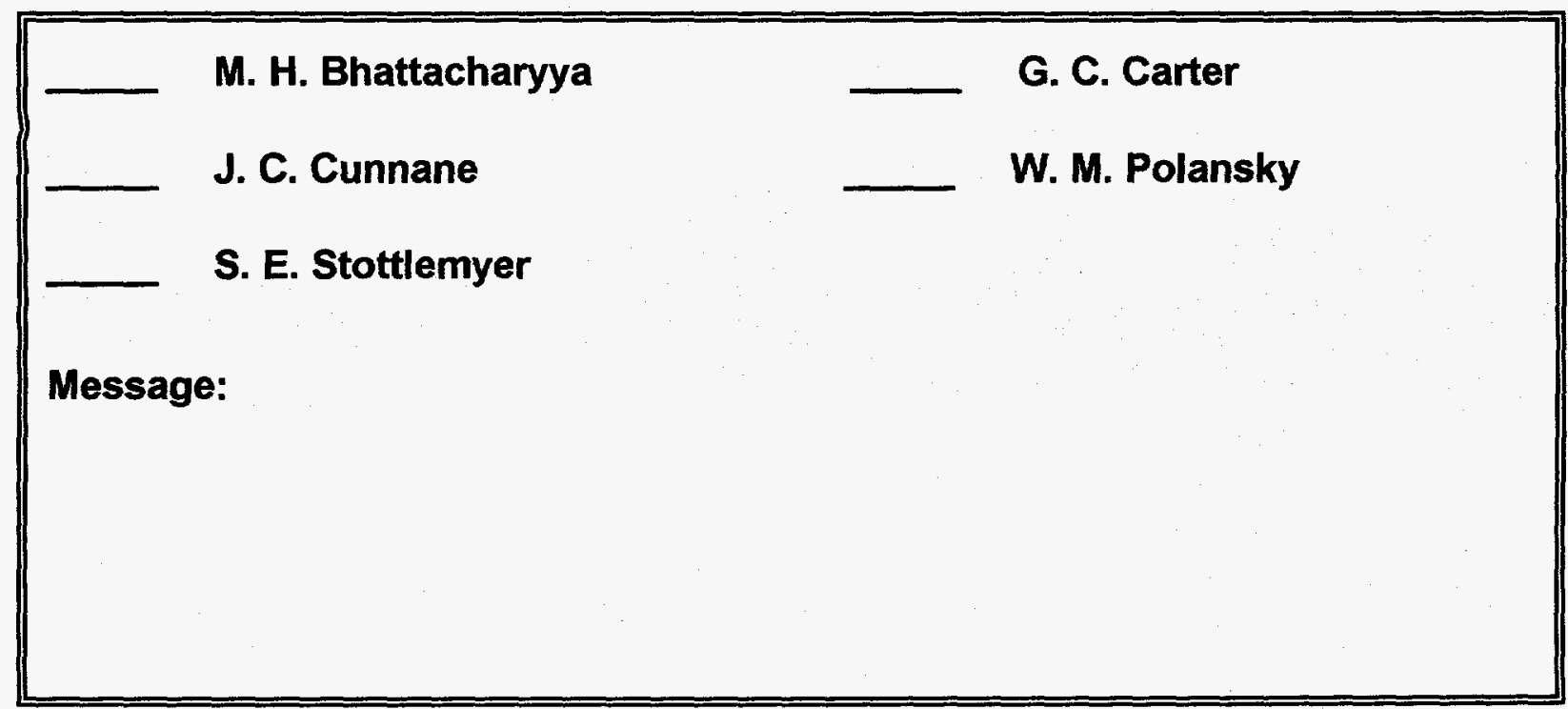

This document consists of pages (including this cover).

TRANSMIT: 301/903-6067

VERIFY: $301 / 903-5995$ 